E UROPEAN CENTRAL BANK

WORKING PAPER SERIES

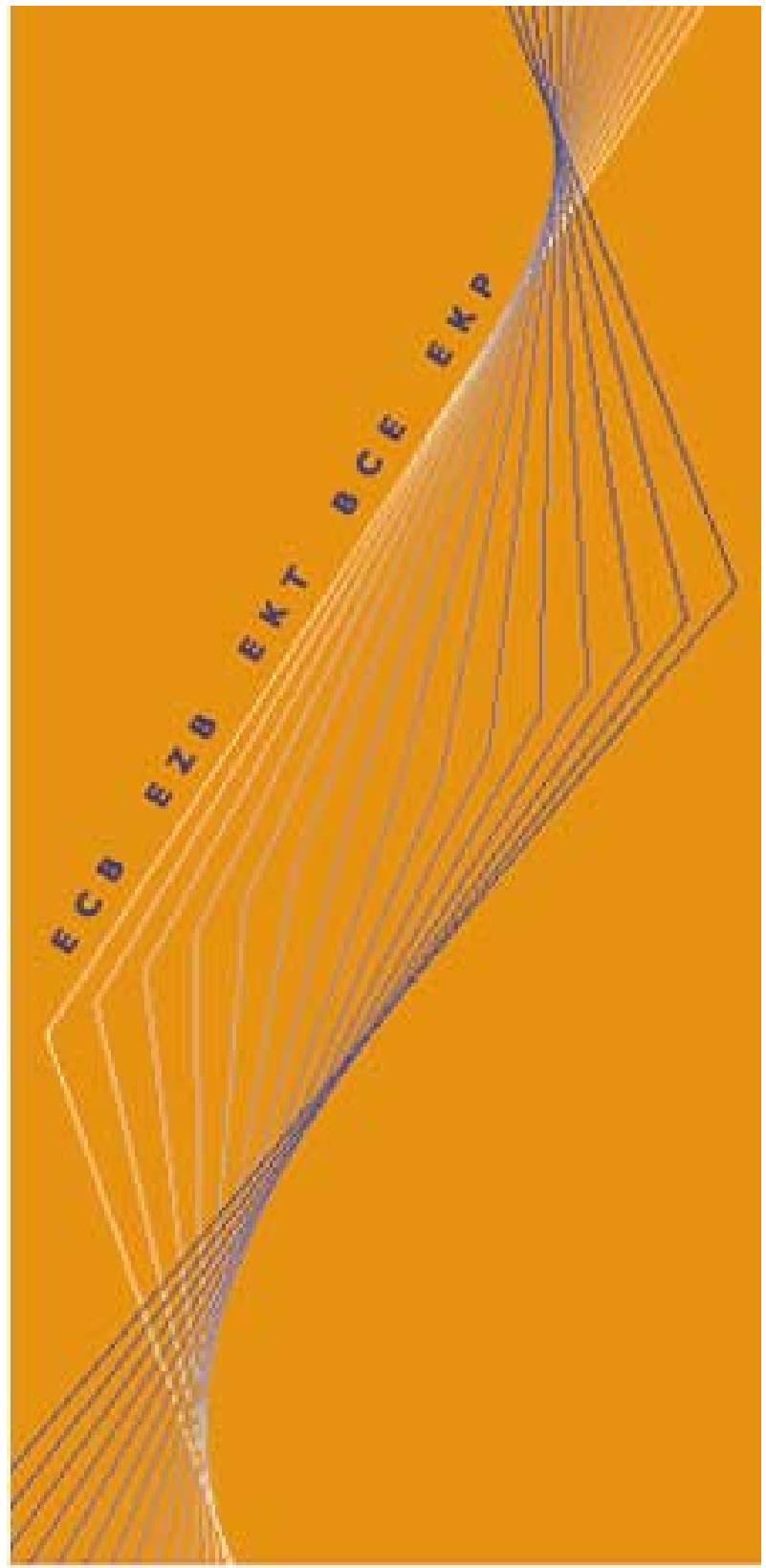

WORKING PAPER NO. 6 I

DIFFUSION INDEX-BASED

INFLATION FORECASTS

FOR THE EURO AREA

BY ELENA ANGELINI, JÉRÔME HENRY AND

RICARDO MESTRE

April 2001 
E U R P E A N C E N T A L B A N K

\section{WORKING PAPER SERIES}

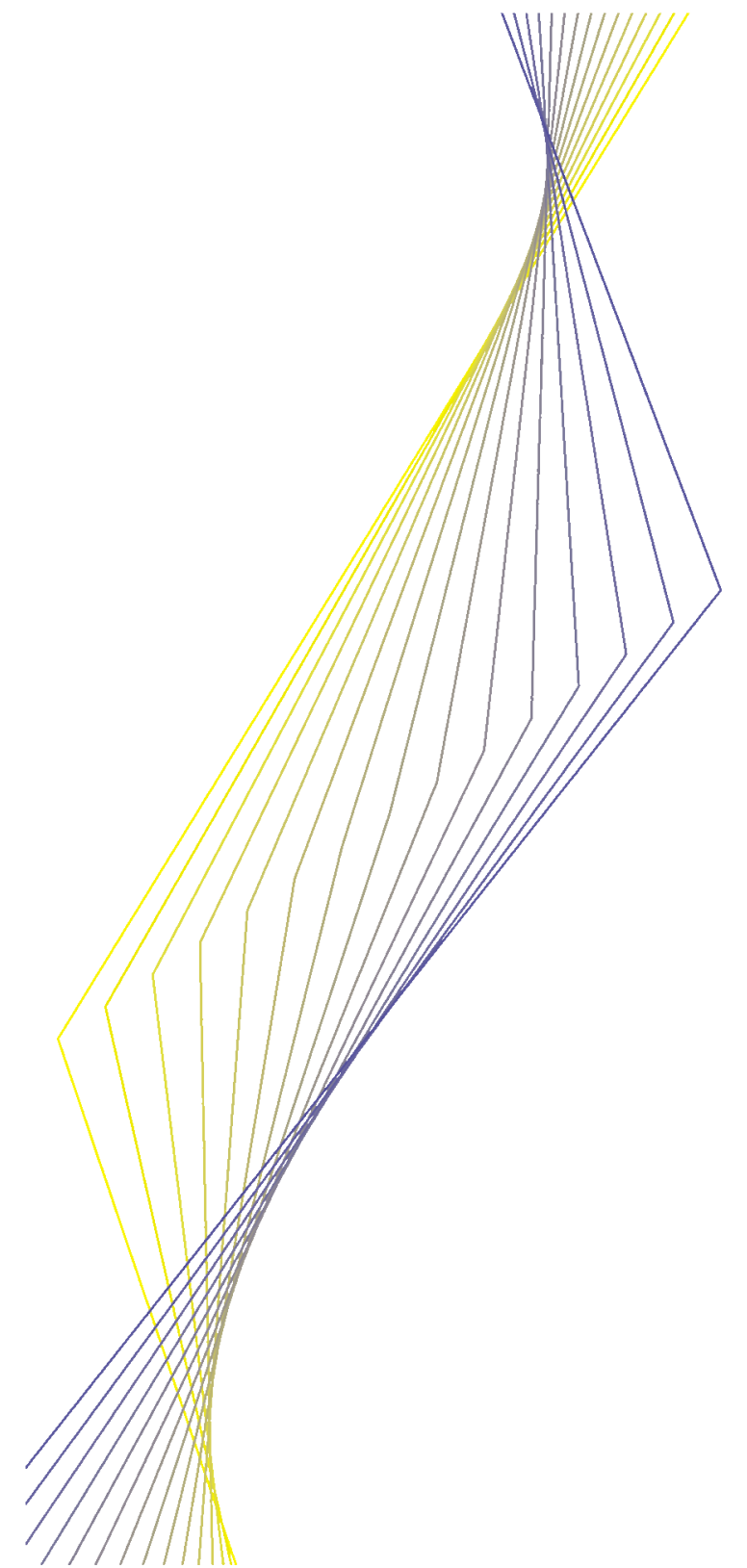

WORKING PAPER NO. 6 I

DIFFUSION INDEX-BASED

INFLATION FORECASTS

FOR THE EURO AREA*

\section{BY ELENA ANGELINI, JÉRÔME HENRY AND \\ RICARDO MESTRE}

April 2001 
(C) European Central Bank, 200 I

$\begin{array}{ll}\text { Address } & \text { Kaiserstrasse } 29 \\ & \text { D-603 I I Frankfurt am Main } \\ & \text { Germany } \\ & \text { Postfach } 1603 \text { I9 } \\ \text { Postal address } & \text { Germany } \\ & +4969 \text { I344 } 0 \\ \text { Telephone } & \text { http://www.ecb.int } \\ \text { Internet } & +4969 \text { I344 } 6000 \\ \text { Fax } & 41 \text { I I44 ecb d } \\ \text { Telex } & \end{array}$

All rights reserved.

Reproduction for educational and non-commercial purposes is permitted provided that the source is acknowledged.

The views expressed in this paper are those of the authors and do not necessarily reflect those of the European Central Bank.

ISSN I56I-08I0 


\begin{abstract}
Diffusion indexes based on dynamic factors have recently been advocated by Stock and Watson (1998), and further used to perform forecasting tests by the same authors on US data. This technique is explored for the euro area using a multi-country data set and a broad array of variables, in order to test the inflation forecasting performance of extracted factors at the aggregate euro area level. First, a description of factors extracted from different data sets is performed using a number of different approaches. Conclusions reached are that nominal phenomena in the original variables might be well captured in-sample using the factor approach. Out-of-sample tests have more ambiguous interpretation, as factors seem to be good leading indicators of inflation, but the comparative advantage of the factors is less clear. Nevertheless, alternative indicators such as unemployment or money growth do not outperform them.
\end{abstract}

Key words: forecast, euro area, dynamic factors, inflation. 


\section{Diffusion Index-based inflation forecasts for the euro area}

\section{Non Technical Summary}

In a recent and influential paper, Stock and Watson (1998) have initiated an interesting line of research by proposing the use of dynamic factors - extracted according to their own specific methodology - as potential indicator variables for future inflation. The approach has already been applied in a companion paper (see Angelini et al. [2001]) which focused on trend inflation in the euro area.

The current paper extends our previous work in three respects. First, the extracted factors are systematically and more deeply analysed in terms of their ability to forecast inflation. Second, factors associated to non-price variables also receive a great deal of attention, whereas the companion paper was restricted to nominal variables. Finally, a thorough analysis of the basic insample properties of the factors is done at a more descriptive and detailed level.

One first result of the analysis is the (apparently) fundamental simplicity of nominal phenomena: price variables are mainly driven by a single factor mostly unrelated with other factors, while nonprice developments show much more complex patterns. This would point to a predominantly simple nominal behaviour in the dataset, compared to a much more complex behaviour for the rest of the variables. Furthermore, factors seem to have relatively minor country-specific content.

On the other hand, the out-of-sample forecasting evidence found is fairly complex to describe, whereas the conclusion that nominal factors are the most relevant for inflation is partially reversed. Factors - and not only those reflecting nominal developments - may be good leading indicators of the various measures of inflation considered, particularly at medium term horizons (4 or 8 quarters ahead). More precisely, HICP inflation is best forecast using nominal factors, while other measures of inflation, for example based on the GDP deflator, is best predicted using non-nominal factors. The consumption deflator is the most difficult to forecast, but shows a pattern similar in general terms to that of the HICP. Indicators other than factors appear in most cases to have slightly worse forecasting properties, although the unemployment rate shows promising results, as well as M3, which leads inflation in many of the cases analysed. Finally, the results attained seem to point to an important structural break around 1992, although evidence presented is not fully sufficient to draw firm conclusions on this issue. 


\title{
DIFFUSION INDEX-BASED INFLATION FORECASTS FOR THE EURO AREA
}

\author{
Elena Angelini, Jérôme Henry, Ricardo Mestre
}

\section{Introduction}

One important development over the last few years has been the steadily growing flow of information accruing to the economist; data is becoming increasingly available at a higher degree of disaggregation, at the regional, temporal or sectoral levels. The availability of such new information has boosted economic analysis in directions other than the traditional economy-wide macroeconomic approach, such as e.g. firm-level panel or high-frequency data analysis. However, macroeconomics could also profit from this richer environment, and research along these lines is nowadays a priority. In this respect, one way to circumvent the relative scarcity of data covering a long period of time for the euro area is to use as much data as are available for all of the member countries. In stark contrast with the area as a whole, most member countries have a long and well-established tradition of collecting a broad range of data, for which long timeseries are therefore available. It is thus particularly important for the analysis of euro area data to explore new techniques or adapt old ones, which would enable the economists to exploit large amounts of country data with only a partial geographic coverage of the area. This paper examines one of these new techniques, with a view to analysing the links between country data of the most diverse nature and a variable of a primary interest to the ECB, namely area-wide inflation.

In a recent and influential paper, Stock and Watson (1998) have initiated an interesting line of research by proposing the use of dynamic factors - extracted according to their own specific methodology - as potential indicator variables for future inflation. Further, the same authors thoroughly analysed the relative forecasting performance of such factors (see Stock and Watson [1999]) with results that, although far from conclusive, are at least promising. The proposed methodology falls within the dynamic factor analysis in line with research going back to Sargent and Sims (1977) or Quah and Sargent (1993) and continued in recent papers such as e.g. Forni and Reichlin (1998), Forni et al (1999) or Forni and Lippi (2000). The approach advocated by Stock and Watson (1998) is being 
applied in a number of related studies, examples of which for the euro area are Marcellino et al. (2000) or a companion paper to this one (see Angelini et al. [2001]). In the latter paper, factors are extracted from a large data set of EMU country-level measures of prices with a view to summarising trend inflation in the euro area into a limited number of indicators.

The main goal pursued in this paper and its companion is to assess ways in which the very rich set of data available for the 11 countries of EMU (12 since early 2001) can be exploited for the benefit of the common monetary policy. In a sense, and bearing in mind the obvious differences, the euro area faces a situation akin to that faced by a country with extensive, high-quality regional data. One possible way to exploit this wealth of data is by directly addressing analyses and forecasts at the country level, to be aggregated afterwards to the area-wide level, the so-called "bottom-up" approach to forecasting. Another approach, assessed in this paper and not necessarily at odds with the previous one, is to explore ways to condense country information into a greatly reduced number of series with no significant loss of information at the area-wide level, thus exploiting country information without loosing sight of the area-wide perspective.

The current paper goes beyond our previous work in three respects. First, the extracted factors are systematically analysed along a dimension which was only marginally addressed previously, i.e. their ability to forecast inflation. Second, factors associated to non-price variables also receive a great deal of attention in the following, whereas the companion paper was restricted to factors derived from nominal variables. Finally, a thorough account of the basic in-sample properties of the factors is done at a more descriptive and detailed level than before.

The paper is structured as follows. Section 2 briefly recalls the technical background of the factor extraction procedures, and discusses a number of practical problems found in this process. Resulting factors are then described in section 3. Section 4 gives details on the forecasting exercise performed, both in terms of the tools (i.e., the 'models' assumed to hold) and of the tests for forecasting ability. Section 5 presents and comments the results. Section 6 concludes.

\section{Factor Extraction}

It is worth highlighting at this point some technical aspects of the approach. ${ }^{1}$ The method uses principal component analysis to extract information from large macroeconomic datasets. Initial raw data are present in the form of a large number of variables related to

\footnotetext{
${ }^{1}$ For a more detailed discussion, the reader is referred to Stock and Watson (1998) or, for a less technical description, to Angelini et al. (2001).
} 
the euro area, from which common factors are extracted following standard statistical procedures in a non-standard framework. The analysis starts with a dataset, of possibly large dimension, containing raw variables assumed to be generated by a small number of common factors, as represented by variable $x_{t}$ in expression $(1.1) .^{2}$ Variable $x_{t}$ is a column-vector representation of $N$ different variables for period $t$, the total number of observations being $T$. In the expression, $x_{t}$ is an $N$-column vector, $f_{t}$ is an $r$-column vector (the factors) and $\Lambda$ is a matrix with $N$ columns and $r$ rows (the loadings). Variable $\varepsilon_{t}$ is an error process uncorrelated with the factors. If all the variables indexed by $t$ are stacked for the $T$ periods of the sample, expression (1.2) results, in which stacked variables appear in upper case.

$$
\begin{aligned}
& x_{t}=f_{t} \cdot \Lambda+\varepsilon_{t}, \quad t=1, \ldots, T \\
& X=F \cdot \Lambda+\mathrm{E}
\end{aligned}
$$

Factors in (1.2) have to be uncorrelated among them and with the residual E (i.e., $\varepsilon_{t}$ in stacked form), and must be such that the variance of the residual is minimised. As shown by Stock and Watson (1998), under fairly general conditions the factors can be estimated - up to a rotation matrix - by standard principal component analysis based on the $N x N$ cross-moments matrix $X^{\prime} X$ or alternatively on the $T x T$ matrix $X X^{\prime}$. As is standard, there is a one-to-one mapping - again up to a rotation matrix - between the two approaches, the preferred one being based on the relative size of the two dimensions. In the dataset analysed below the latter approach is taken, as its time dimension is smaller than the variable dimension. One key decision in the analysis is the number of factors that have to be extracted, which can range from 1 to (in the case at hand) $T$. Although some methods have recently been proposed in the literature to test and choose the underlying number of factors (see e.g. Bai and $\mathrm{Ng}$ [2000]), the approach followed in this paper has been simpler. Forecasting tests have been performed with alternative numbers of factors, with an upper limit on their number imposed not by the econometrician but by the quality of the estimated factors in terms of variance explained and also their robustness to missing observations.

One advantage of this approach is the possibility of using expanded sets of information in deriving the factors, i.e. the possibility of using information from variables that do not cover the whole period in order to fine-tune the estimation of the factors. Variables that are not present for some periods (i.e. variables with missing values for part of the sample) can nevertheless be used to extract factors, thanks to a slightly more complex factor estimation procedure, as shown by Stock and Watson (1998). The principal component approach described in the previous paragraph, and the corresponding matrix

\footnotetext{
${ }^{2}$ Lags of the factors can enter (1.1) without loss of generality. Mild time variation in $\Lambda$ is also possible.
} 
decomposition problem, is only valid in the presence of complete datasets, i.e. datasets in which no data are missing (a situation termed as balanced panel). Stock and Watson (1998) show that maximising the likelihood of the system (1.2) in the case of a balanced panel results in a standard matrix decomposition problem, but they also prove that it is still possible to perform the estimation in the presence of incomplete information using the well-known EM algorithm. In this case, the system (1.2) itself can be used to derive expected values of missing variables (the E step), which can then be used to maximise the system (the M step). The final estimates result from iterations on these two steps until final convergence. It is obviously necessary to provide initial estimates of the parameters for the first iteration. Following a proposal made by the two authors, the initial factors will be given by the larger data set covering the full sample with no missing data, i.e. the largest subset of the original data set providing a balanced panel. ${ }^{3}$

Given the situation for euro area data, characterised by missing observations for a number of countries, it is important to understand the process by which the EM algorithm can be applied to unbalanced panels. Starting from some initial estimates $\hat{F}$ of the factors and $\hat{\Lambda}$ of the loadings, an estimate of the complete dataset is obtained by replacing missing values in $x_{t}$ with corresponding elements of $\hat{x}_{t}=\hat{\Lambda} \cdot \hat{F}$. A corresponding crossmoments matrix can be formed from the generated variables, and factors and loadings reestimated. Each time an iteration is run new factors are extracted and used in the following iteration. One important aspect of this algorithm is that iterations can be made taking all eigenvalues of the matrix, or selecting only those most significant. Although both approaches provide asymptotically correct estimates of the true factors, the smallsample properties could differ markedly. In the case at hand, this may have had an important impact on the calculations.

Data used in this paper relate to the 11 countries of the area that were taken into consideration (i.e. members before 2001) and cover a broad array of economic items. The rather large dataset comprises 278 variables spanning the period from (roughly) 1977 to 1999. A fuller description of the variables, with a breakdown by country, is included in Appendix C. Most series are of quarterly frequency, and those present at monthly frequency were transformed into the lower frequency, because of the lack of monthly data for many series used and also the sensitivity of the results to missing observations when the latter become too numerous, as described below. One notable feature of the series is the presence of nominal and real variables in the dataset from which factors were extracted, which raises the possibility of separating purely nominal factors from other influences affecting inflation. This is a desirable feature. The analysis has thus proceeded with two different sets of dynamic factors: first, those extracted from purely

\footnotetext{
${ }^{3}$ Other options are available which are worth exploring, due to the high likelihood of the last observation being sparse. This paper does not explore these alternatives, but this is a point on our agenda.
} 
nominal information (i.e., deflators, wages and prices contained in the original database) and, second, all-encompassing dynamic factors as obtained from the complete dataset. Furthermore, some interesting facts were discovered regarding factors extracted from a dataset comprising all the variables except those used for the nominal-only factor extraction. The three sets of factors will be discussed, with a special emphasis on factors extracted from the all-encompassing dataset.

Original series were firstly checked for the presence of outliers and then transformed to get rid of non-stationarity and heteroskedasticity, by taking logs or ratios of variables and differencing the series appropriately. Further to that, all series were standardised by removing their mean and dividing them by their standard error. Factors extracted from the complete dataset will be termed 'overall factors', those extracted from a dataset comprising only prices will correspondingly be termed 'nominal factors' and those extracted from non-price variables, 'non-nominal factors'. As already mentioned, nominal factors are already extensively analysed in the companion paper, see Angelini et al. (2001).

As documented and discussed in detail in Angelini et al (2001), a number of numerical problems appear when estimating factors from an unbalanced panel. When the number of factors selected in each EM iteration (see above) is relatively large (three or four in our case), distortion in the final estimates can be present and unbalanced-panel factors can considerably differ from balanced-panel ones and end up being much less plausible. In the present case, a closer inspection of results highlighted a couple of interesting points. First, the degradation of results in unbalanced-panel estimation is not gradual but increases visibly when more than three or four factors are used in the EM iterations. Second, this is especially the case for the 'nominal factors', for which results are affected as soon as three factors are computed. ${ }^{4}$ In turn, 'overall factors' remain plausible when computed with the unbalanced panel until up to five factors are taken into account in the EM algorithm. Finally, 'nominal factors' were significantly different when using balanced or unbalanced panel estimation, while 'overall factors' were much more robust to the inclusion of series with missing observations.

\footnotetext{
${ }^{4}$ Additional information, including charts, regarding the unbalanced-panel distortion with 5 factors may be found in the companion paper.
} 


\section{Chart 1. Comparison of factors}
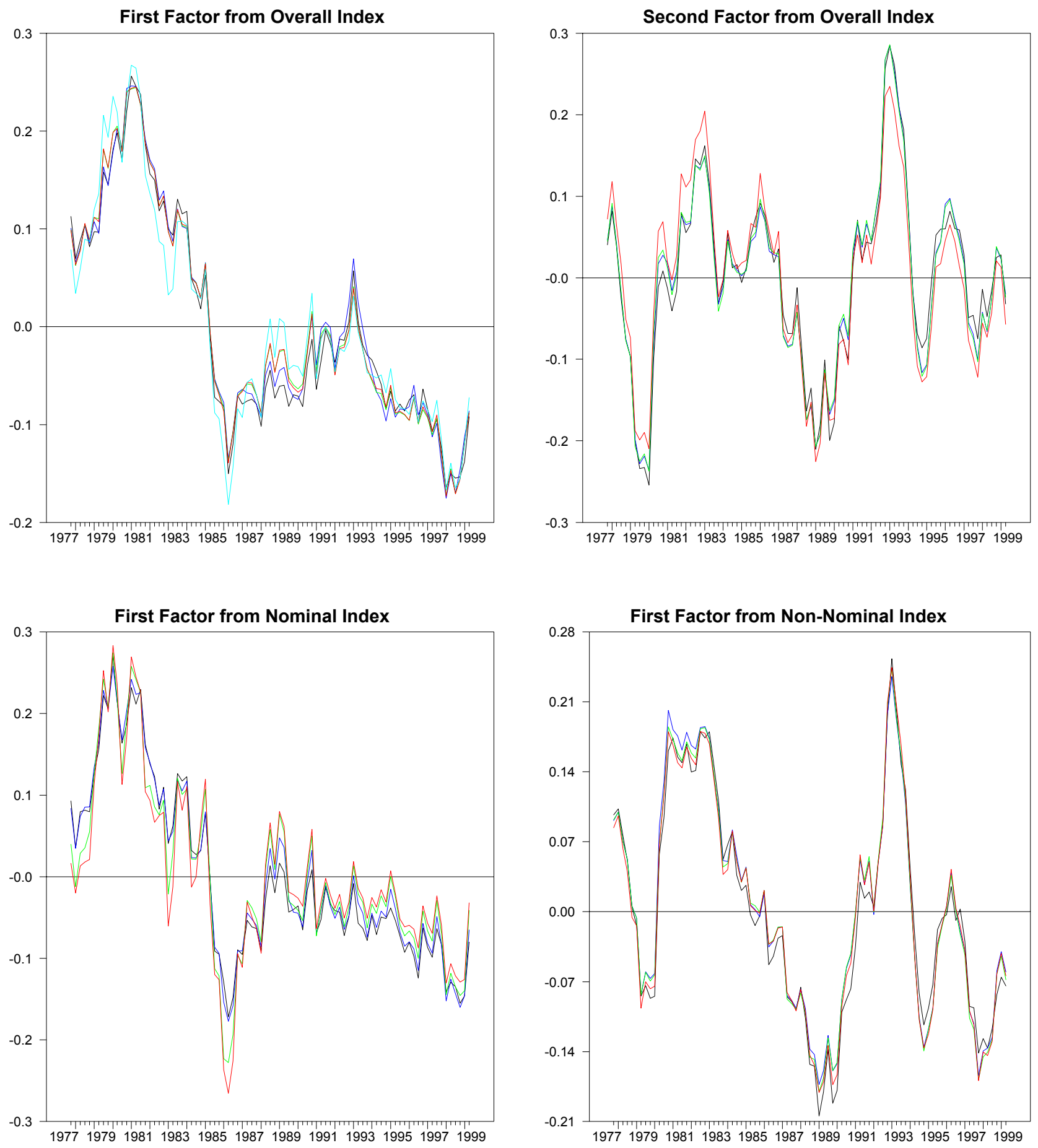

A graphic representation of the 'overall factors' is shown in Chart 1. The first panel on the upper left-hand side shows the first 'overall factor' for all estimations, i.e. for the balanced panel and the unbalanced panel with respectively one-, two-, three- and fourfactor EM iterations. The upper right-hand-side panel of Chart 1 shows correspondingly 
the second 'overall factor' for the balanced panel and the unbalanced panel with respectively 2-, 3- or 4-factor estimation. (Obviously, no second factor was extracted in 1-factor unbalanced-panel estimates.) Although not reported, the 'nominal factors' also showed some (lesser) degree of stability across models, with the exception that at most 3factor EM iterations were acceptable instead of 4 -factor estimations. Beyond this number (i.e., for EM iterations taking four or more factors) results were clearly unsatisfactory.

The two lower panels of Chart 1 depict another interesting fact about these estimates. They show the first 'nominal factor' and the first 'non-nominal' factor, to be compared with the 'overall factors' of the upper panels. These results clearly point to very different profiles for the factors according to the information used to extract them. On the other hand, the first 'overall factor' is visibly similar to the first 'nominal factor', while the second 'overall factor' looks very much like the first 'non-nominal factor'. Very likely, there is a clear separation between 'nominal' and 'non-nominal' factors in the dataset used. Although it is true that the estimated factors can be rotated, the features just described seem to be able to withstand any possible rotation. (As a matter of fact, finding criteria to rotate the factors in a homogenous way would seem a desirable development of the technique. $)^{5}$

\section{Analysis of extracted factors}

Factors extracted following the mentioned methodology may serve many different purposes. It has become standard in the literature to assume that they correctly summarise the economy the initial variables refer to, and thus may be a good indicator of important forces underlying the economy. In particular, it has been advocated that these factors may provide good leading indicator properties and may thus show good forecasting ability (see Stock and Watson [1999]). The main aim of this paper is to test this specific feature of the estimated factors, both the 'nominal' and the 'overall' ones. It is nevertheless necessary to give first some broad overview of the basic features of the factors obtained, both in terms of their shape and of their relationship with the original variables.

Probably the most notable feature of the three sets of factors (i.e., overall, nominal and non-nominal factors) is the striking similarity of pattern between, respectively, the first 'overall' and the first 'nominal' factors, and also the second 'overall' and the first 'nonnominal' factors, as already seen on Chart 1.

Another interesting feature is the lower percentage of the variance explained by the first few factors in the 'overall' case: while the first 'nominal factor' explained $59 \%$ of the

\footnotetext{
${ }^{5}$ All the charts show the factors estimated with the full sample. Factors were estimated recursively in the course of the forecasting test and found to be relatively stable when increasing the estimation sample.
} 
variance of prices, the first 'overall factor' only explains about $25 \%$ of the corresponding data variance. Not surprisingly, the first - i.e. most important - 'non nominal factor' also explains only a tiny fraction of data variance, thus giving clear indications that the variance in the nominal dataset is highly concentrated around a small number of factors, whereas the non-price system of variables seems to be of a more intricate nature. ${ }^{6}$

Links between factors and variables is also a relevant piece of information, which can be best analysed using the estimated loadings. The latter express the projection of the factors onto the variables, variable $\Lambda$ in expression (1.1). With a convenient re-scaling of the factors, the loadings must lie between -1 and 1, thus giving a direct and easily readable measure of the goodness of fit of the projection for each variable. In fact, loadings give a measure of the correlation between factors and each variable since both factors and variables have been normalised beforehand and have thus unit variance. Further, the fact that factors are uncorrelated means that loadings squared can be read as $\mathrm{R}$-squared measures of the regression of individual factors on each variable. Tables 1 and 2 in Appendix A show the loadings and its squares for all the variables, distinguishing between variables in the balanced panel and those entering only the unbalanced panel. ${ }^{7}$

A quick overview of the tables in Appendix A leads to a number of general conclusions. First, the first 'overall factor' is very similar to the first 'nominal factor' also in view of the loadings. ${ }^{8}$ The table confirms indeed that most, if not all, price variables are strongly correlated with this factor. Other variables with a significant relationship with this factor are earnings, employment and unemployment series, most notably the unemployment rate. More striking is the fact that survey variables related to manufacturing also show a visible degree of correlation: capacity utilisation, order-book commands, new orders or stocks in manufacturing firms. The rest of the variables are clearly less related to this factor, most notably GDP and monetary aggregates.

In general terms, the second 'overall factor' is much less correlated with variables, although capacity utilisation, survey-based manufacturing series, earnings, employment and unemployment show some relatively sizeable degree of correlation with it. In fact, these series share some degree of correlation with both factors. Another interesting point is the relatively high correlation between the second factor and the short- and long-term interest rates, which on the other hand are not strongly correlated with the first factor. Variables belonging to the expenditure side of National Accounts do not show a clear-cut correlation pattern with any factor, i.e. GDP, Private Consumer Expenditure, Exports or Imports, nor do retail-sales variables.

\footnotetext{
${ }^{6}$ As the data set termed as non-nominal comprises variables usually treated as nominal - foremost among them, money - it is not possible to assign this complexity only to real-activity variables.

${ }^{7}$ For those variables entering both the balanced- and unbalanced-panel estimation, corresponding loadings were similar.

${ }^{8}$ Loadings for the 'nominal factors', in a format similar to table 1 can be found in Angelini et al. (2001).
} 
Regarding unbalanced-panel estimates, caution is needed in interpreting them because of the somewhat more complex estimation method used. Caution is particularly needed for the second and third factors, for which there is evidence of increasing distortion. Nevertheless, results show that the first 'overall factor' is still correlated with price variables, although evidence is less compelling than in the balanced panel. For the other variables and factors, it is more difficult to extract unambiguous conclusions.

Last but not least, country-specific evidence is not strong. Most countries show specific correlation patterns for a few variables, but not as a general feature. Finland is probably the clearest case of a general specificity. All in all, correlation patterns along variables are stronger, or at least more visible than along the country dimension.

\section{Forecasts}

As mentioned in previous sections, the backbone of the analysis herein is an exploration of the inflation forecasting ability of factors, with a particular emphasis on the euro area. In line with previous and related studies, the current section presents a discussion of the specific forecasting techniques that are to be used for the exercise.

Three preliminary steps need be covered before going further. It is first of all necessary to spell out clearly what is the real-life problem one is expected to face. In our case, the main centre of focus is on how to forecast the inflation rate of the euro area. Furthermore, and secondly, it is important to describe (and try to approach in the analysis) the real circumstances in which the actual forecast may take place. Regrettably, real-life forecasts based on dynamic factors are difficult to replicate ex-post: they usually involve large amounts of data, much of which are provided with lags and delays and are also likely to be revised subsequently. The framework of our analysis will be simpler than the real-life task in that a final, fully revised dataset will be used, but some degree of realism will be achieved by performing true out-of-sample forecasts based on this dataset. As a third and final step, it is important (although maybe less critical) to set the general technical procedures that might be followed to perform the forecasts themselves. Most forecasts embody a lot of discussion among participants with heterogenous background and views, and probably will include some degree of judgement. The analysis in this paper, on the other hand, is restricted to automatic and simple procedures, which cannot reflect a more protracted and complex forecasting process. The strength of the analysis will rather lie in the many replications of simulated out-of-sample forecasts and their comparison with a pre-defined benchmark forecasting tool or model, in the belief that procedures able to beat consistently the benchmark are worth being developed further. In this, we follow an entirely standard approach within the literature (cf. Stock and Watson [1999]). 
In line with the stated goals, the forecasting exercises are performed on three alternative measures of the euro area inflation rate: the Harmonised Index of Consumer Prices (HICP), the consumption deflator and the GDP deflator of the ESA95 euro area national accounts. Data limitations prevent the use of raw data, as it covers only a relatively short amount of time, and force some pre-treatment of the data: the three series were backdated with data coming from the OECD. ${ }^{9}$ Moreover, it was decided to focus on quarterly forecasts due to the quarterly nature of the last two variables, but also because of the much richer set of quarterly series that were available for extracting the factors. Last but not least, the problems with unbalanced-panel estimations already mentioned militated against carrying out the analysis at the higher frequency. Obviously, this is a limitation of the analysis that has to be lifted as soon as possible, e.g. by collecting as much monthly data for the euro area member states as is available.

As said, no attempt was made to replicate true forecast circumstances, as it is for the time being prohibitively expensive to prepare a real-time dataset with an accurate representation of the real state of information at each point in time. As has become standard in most of the related literature, the way to approximate this situation has been by using a single final (i.e. fully revised) dataset covering the whole period, but performing rigorous out-of-sample forecasts using no information belonging to periods later than that at which the forecast is assumed to take place. ${ }^{10}$

The simple techniques followed to derive the forecasts are also fairly standard. A growing body of literature has recently performed thorough testing exercises of the forecasting ability of sets of variables by running regressions based on (3.1), in which $y_{t}$ is the variable of interest, assumed to be $\mathrm{I}(1), z_{t}$ is the indicator variable under test, assumed to be I $(0)$, and $\varepsilon_{t}$ a well-behaved error term. In the expression, $h$ stands for the number of periods ahead for which the forecast has to be performed. This expression assumes that there exists a direct mapping from $\mathrm{I}(0)$ variables known today to information $h$-periods ahead. Interestingly, all information required to do the forecast is assumed to be already available, and thus describes a system in which no recursion is needed to obtain the forecast.

$$
\frac{y_{t+h}-y_{t}}{h}=A(L) \cdot \Delta y_{t}+B(L) \cdot z_{t}+\varepsilon_{t}
$$

\footnotetext{
${ }^{9}$ Refer to the discussion in Angelini et al (2001) and references therein.

${ }^{10}$ Bernanke (2000) argues that gains in the analysis from dealing with a true real-time data set may be smaller than previously thought. It may be worthwhile nevertheless to at least replicate in a more realistic setting the true-life exercise by performing Monte-Carlo simulations with fake revisions to data known to be revised, a task left for further research.
} 
Expression (3.1) is not the standard approach taken to model dynamic systems outside this brand of literature. Normal procedure is to assume that a 1-step-ahead recursive system like (3.2) applies. This equation seems to be preferable to (3.1) as it apparently uses more information, but this is misleading because our main interest is in deriving forecasts $h$-periods ahead based on factual data. Equation (3.2) provides such a forecast by recursively generating the periods in between, and thus adds no new information.

$$
\Delta y_{t+1}=A(L) \cdot \Delta y_{t}+B(L) \cdot z_{t}+\varepsilon_{t}
$$

Although (3.1) is nowadays customarily used to make out-of-sample forecasts (see e.g. Stock and Watson [1999], Bernanke [2000] or Marcellino et al. [2000]), it is worthwhile exploring the actual differences between the two expressions. Such a step has, to the best of our knowledge, been skipped in the factor-forecast literature, although, in view of the standard practices of professional forecasters, the lack of explicit discussion on this difference could cast doubts on the results obtained. Indeed, most professional forecasters would, if they had to forecast variable $y_{t+h}$, spend a great deal of time considering the expected evolution of $z_{t}$, and its impact on $y_{t+h}$. Thus, they would naturally prefer a forecasting framework described by (3.2). This framework is however at odds with the philosophy of dynamic-factor forecasting, precisely because there is in principle not much to be said on the future evolution of the factors. A thorough analysis of the relative forecasting performance of the two approaches is thus warranted. A description of an analysis along these lines is reported in Appendix B, in which the conclusion is reached that for the sample used it is likely that both systems have similar performance.

\section{Results}

Once the factors have been extracted and the forecasting equations chosen, it remains to tackle practical decisions such as which variables to forecast, or what indicators to use as benchmarks against which to compare the performance of the dynamic factors. Another practical matter relates to the choice of lags in the forecasting equation, as this was left undefined in the previous section. Finally, it is necessary to set the number of periods ahead that will be tested, and the break date after which the out-of-sample exercises will begin.

As already stated, the basic aim of the paper is to measure accuracy in performing (simple) inflation forecasts. As said, three variables were retained as measures of inflation: the euro area-wide Harmonised Index of Consumer Prices (HICP), the euro area Private Consumption deflator and the corresponding GDP deflator. The three indexes were treated as $I(1)$ variables, resulting in an assumed $I(0)$ inflation rate. Indicators retained included the 'overall', 'nominal' and 'non-nominal' factors from the 
balanced panel and the unbalanced panel with 1-, 2- and 3-factor extraction. Alternative indicators employed to forecast the euro area inflation were: the euro area unemployment rate, GDP growth, the output gap in the form of a Hodrick-Prescott-filtered GDP, and growth of nominal M3 ${ }^{11}$ Both the factors and the output gap were extracted in real-timelike manner, i.e. were calculated from anew each time the starting date for the out-ofsample exercise was changed. The rest of the indicators (i.e., the unemployment rate and output growth) came from a final database and were thus simply extracted from it after dropping the unneeded observations beyond the starting date of the out-of-sample test.

Contrary to the rest of the indicators, dynamic factor equations could comprise more than one indicator variable, as sometimes more than one factor is used. The simplest equation employed contains only the first factor of, respectively, the 'overall', 'nominal' or 'nonnominal' datasets. Additional factors are added sequentially, first the second factor added to the first one, and then finally the third one added to the other two. To ensure consistency, unbalanced-panel factors appearing in an equation are always derived from the same underlying estimation, i.e. the first factor appearing in an unbalanced-panel equation with (say) three factors has to come from the 3-factor EM estimation. So doing it is possible to exploit the natural ranking of factors, since sequentially each one explains less variance of the original dataset. No such natural ranking of indicators is present with observed variables; therefore the other indicators are used in isolation in their own forecasting equation.

As regards multiple-factor regressions, it has become customary to either fix the number of parameters or select them following some information criteria such as the BIC. This option was not followed in this paper because of potential small-sample problems, and the known tendency of some information-criteria tests to overstate the number of variables to pick up. Instead, a thorough testing of different combinations of factors was preferred. Hence, out-of-sample forecasts were first run with the first factor, then with the first and second factors, and finally with the first three factors. As already mentioned, the numerical problems found in the derivation of the fourth factor in the unbalanced panel with nominal variables (the fifth one, in the case of the complete database) justified taking into consideration only the first three factors. All factors entered with two lags, although different numbers of lags were tested.

Another key choice to make is the number of lags of the dependent variable entering the forecasting equation (i.e., $\Delta \mathrm{y}_{t}$ ). There, it is also the standard practice to either fix them a priori or choose them based on an information-criteria test. We have in this case slightly departed from any of these choices and have, after a large number of tests, decided to take as many lags as periods ahead to forecast. Thus, our number of lags is $h$ and is made

${ }^{11} \mathrm{M} 1$ and M2 were also tested, as were real M1, M2 and M3. Nominal M3 was clearly the preferred choice. 
dependent on the particular forecasting horizon. This approach was taken after an exploration of alternative settings, and probably is a reflection of the relatively high persistence of inflation, as this imparts a lot of inertia to the dependent variable that may not be well captured unless horizon-dependent number of lags of $\Delta y_{t}$ are added. (It is important to notice that the chosen equations are not recursive and are thus probably less prone to over-parameterisation problems.)

Results are presented in the form of relative RMSE of each equation against a convenient benchmark, for different forecasting horizons. The chosen benchmark is a simple version of (3.1) in which no indicator is used. Alternative specifications include as indicators the unemployment rate, GDP growth, the output gap and growth of M3. Dynamic factors comprise from 1 to 3 factors of the balanced and unbalanced panels. Each time, forecasting equations are estimated for a conveniently chosen sub-sample, out-of-sample forecasts done for the necessary steps ahead or until the end of the full sample was reached, and corresponding RMSEs collected. The same operation is repeated for longer sub-samples (extended recursively), each time collecting RMSEs. Finally, all RMSEs are averaged separately for each specific horizon. The RMSE for each combination of equation and horizon is divided by the corresponding one for the benchmark, and the resulting ratio shown on the table. A ratio of less than one means that for that horizon, the corresponding equation can beat the benchmark, the opposite being true otherwise.

This procedure provides estimates of the true underlying forecasting performance of the equation by simple averaging of forecast errors. These forecasts take place within sample, but in periods not used to estimate the equation. At each step it is necessary to split the observed sample between a part dedicated to the estimation and a part dedicated to the calculation of forecast errors. If care is not exercised, a too early split date may lead to inaccuracies in the first estimations, and may bias the resulting RMSE test. Even worse, structural breaks in the data may lead to seemingly large RMSE numbers because of shifts in the forecasts done before any structural break. These problems dictate prudence in setting the initial date at which recursions are started, compounded in our case by the potentially unstable nature of euro area data. Accordingly, a relatively late first date for the out-of-sample exercises was chosen, i.e. 1995Q1. Results for earlier starting dates were performed and are reported, although a structural break before 1995 cannot, in our view, be dismissed so that stronger weight should be put on the findings for 1995Q1.

Results from the forecasts are collected in tables 1, 2 and 3. The first table is our basecase one: it shows results for out-of-sample exercises starting as of 1995Q1; table 2 has the same structure but with the initial date set at 1992Q1; finally, table 3 has an initial date of 1985Q1, beyond which results would become highly unreliable. Each table is in turn divided between forecasts for HICP, for the consumption deflator (labelled PCD) 
and for the GDP deflator (labelled YED). Forecasting accuracy is always measured against a simple forecasting equation with no indicators, i.e. just lags of $\Delta \mathrm{y}_{t}$, labelled in the table as AR. The comparison between the benchmark and each of the alternative equations is done as the ratio of the RMSE of both. (Hence the row of ones on top of each table, in the line corresponding to the benchmark itself.) As in table 1, a value of less than one in a specific cell means that the corresponding equation has been on average more accurate than the benchmark. The comparisons are made for forecasts one to four periods ahead, and to eight periods ahead. The sample used and the date at which out-of-sample tests were started are also included on the right side of the table.

A number of general conclusions can be drawn from the tables.

Factors have in general relatively good forecasting performance, particularly at medium term horizons (beyond 2 quarters). Although factors never fare badly compared to alternative indicators at the one-quarter-ahead range, they have relative RMSEs that are generally lower at four- and eight-quarters-ahead forecasts. Regarding particular measures of inflation, nominal factors are preferable for HICP forecasts irrespective of the break date considered. In particular, forecasting regressions using two or three nominal factors coming from the unbalanced-panel estimates always match the best alternative indicator. To a lesser extent, the same applies for the consumption deflator (PCD in the table), although in this case a general degradation of forecasts can be perceived throughout the tables. On the other hand, the GDP deflator (YED in the table) is best forecast by non-nominal factors, this time by a rather considerable margin. Again, this is particularly true for medium-range forecasts using regressions with two or three unbalanced-panel factors.

Setting the starting date at 1992 Q1 leads to a visible worsening of forecasts. This is an outstanding feature in the tables: for all indicators, including factors, setting the recursion-starting date at 1992Q1 leads to visibly higher RMSEs than in either table 1 or table 3. Again, only the factors mentioned in the last paragraph are able to withstand the change in starting date without large deterioration of results. An intriguing feature of the starting-date comparison, upon which it would be unwise to draw unwarranted conclusions, is the relative similarity between table 1 and 3 (respectively, with dates at 1995Q1 and 1985Q1) compared with table 2. This somewhat surprising feature certainly deserves further investigation since it may suggest that the period between 1992 and 1995 played a particular role in terms of structural changes affecting the underlying forecasting model.

Among alternative indicators (i.e., those not based on factors), unemployment outperforms the rest. The unemployment rate is very often the alternative indicator delivering lower RMSE for most horizons, irrespective of the chosen inflation measure 
or recursion-starting date. On the other hand, M3 is surprisingly good at forecasting HICP for all recursion-starting dates. (See Nicoletti-Altimari [2001] for similar findings.) This feature is, however, not found to hold for the consumption deflator and the GDP deflator, for which M3 has a reasonable but lacklustre performance. Finally, the output gap shows an unpromising forecasting performance, a fact in contrast with its widespread use in the literature but that could originate in the recursive end-of-sample revisions of the series performed. The Hodrick-Prescott filter was run each time an out-of-sample iteration was started, and this led to large revisions of the end point of the resulting output gap series. This conclusion, if granted, would highlight further the well-known problem incurred in using filtered versions of potential output and the ensuing end-ofsample problem.

Additional tests were carried out that are not reported to save space. For instance, adding seasonal dummies and a German reunification dummy improved marginally the forecasting ability of the observed indicators but left almost unchanged that of the dynamic factors. Also, changing the number of lags for all indicators (tests were made for zero lags to four lags), although changing results, did not alter the conclusions reached.

\section{Conclusions}

Past developments in data collection and treatment have led over the recent years to an explosion in the amount of data available for economic analysis. This increasing wealth of data calls for the exploitation of non-standard econometric techniques. This is specially the case for the euro area, for which area-wide-specific data are still a relative oddity but a great wealth of data is available for the member countries. One technique developed recently by Stock and Watson (Stock and Watson [1999]) is pursued in companion paper for the analysis of trends in the euro area-wide inflation (see Angelini et al. [2001]), and is further used in this paper with the particular aim of forecasting areawide inflation. The technique entails summarising a large amount of data into a small number of factors using a form of principal-component analysis, and using the resulting factors to forecast inflation. Technical aspects of the task are described, including data treatment and the set-up used to forecast. Factors are extracted from a broad dataset comprising country data of the 11 member countries ${ }^{12}$, but also from a breakdown of the mentioned dataset between price variables and non-price variables. Variables employed to measure inflation are HICP, the consumption deflator and the GDP deflator, for which simulated out-of-sample forecasts are run, using the extracted factors and a set of alternative indicators.

\footnotetext{
${ }^{12}$ The analysis will be readily extended to the current 12 countries.
} 
A first task reported in the paper is an in-sample analysis of the basic properties of the factors, and their links with the series included in the dataset which they summarise, which is an extension of evidence presented in our companion paper. One outstanding feature discovered is the (apparently) fundamental simplicity of nominal phenomena: price variables are mainly driven by a single factor mostly unrelated with other factors, while non-price developments show much more complex patterns. This feature is apparent by the double coincidence of two facts, namely a very strong first factor for the price-only dataset almost coincident with the first factor of the all encompassing dataset, and lack of strong factors for the rest of variables. Factors are in this case termed as strong both in terms of their in-sample significance in the principal-component problem and their links to specific variables. This would point to a predominantly simple nominal behaviour in the data set, compared to a much more complex behaviour for the rest of the variables. Furthermore, factors seem to be more strongly related to variables as a whole, i.e. the same type of series irrespective of the country, and have therefore relatively minor country-specific content.

On the other hand, the out-of-sample forecasting evidence found is fairly complex to describe. On top of that, the self-evident conclusion drawn from the in-sample analysis that nominal factors are the most relevant for inflation is now partially reversed. The main conclusion is that factors - but not only those reflecting nominal developments may be good leading indicators of the various measures of inflation considered, particularly at medium-term horizons ( 4 or 8 quarters ahead). More precisely, HICP inflation is best forecast using many nominal factors (but not just the first one), while the GDP deflator inflation is best predicted using non-nominal factors. The consumption deflator is the more difficult to forecast, but shows a pattern similar in general terms to that of HICP. Alternative indicators broadly appear to have slightly worse forecasting properties, although the unemployment rate shows promising results while M3 also leads inflation in many of the cases analysed. Last but not least, experiments done changing the date at which the simulated out-of-sample forecasts start show that results are becoming worse for a specific date, 1992Q1. This could be interpreted as a signal of an important structural break around this date, although evidence presented is certainly not sufficient to draw firm conclusions on the issue.

Although the exercises performed in the context of this paper have been kept deliberately simple, they are promising enough to warrant further research, with a view to assessing deeper the specific contribution and relevance of the factor method. In terms of the insample analysis, for instance, performing rotations of factors in order to clarify their relationship with the original variables could further clarify the role of nominal phenomena. Regarding the out-of-sample analysis, two immediate developments of this work could be, first, to exploit the leading-indicator information of the factors as if in real-life, i.e. checking the importance of updates and successive releases of data, and, 
second, to seek new ways of implementing the factor based forecast. An example of the latter could be to extract factors from datasets also including the aggregated area-wide data, drawing thereby forecasts from the extrapolated series for the euro area resulting from the principal-component analysis using jointly all of the country and area-wide information. 
Table 1

HICP

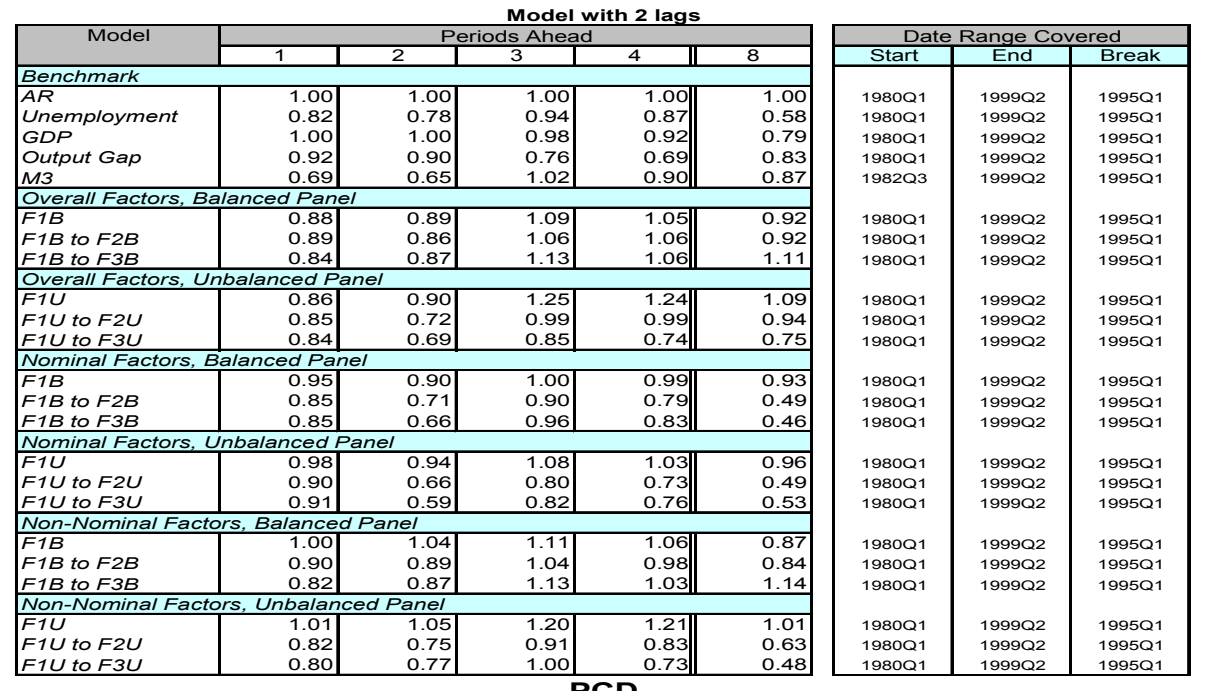

PCD

\begin{tabular}{|c|c|c|c|c|c|c|c|c|}
\hline \multirow{2}{*}{ Model } & \multicolumn{5}{|c|}{ Periods Ahead } & \multicolumn{3}{|c|}{ Date Range Covered } \\
\hline & 1 & 2 & 3 & 4 & 8 & Start & End & Break \\
\hline \multicolumn{9}{|l|}{ Benchmark } \\
\hline & 1.00 & 1.00 & 1.00 & $1.00 \|$ & 1.00 & $1980 Q 1$ & $1999 Q 2$ & 1995Q1 \\
\hline Unemployment & 0.79 & 0.78 & 0.81 & 0.86 & 0.48 & $1980 Q 1$ & $1999 Q 2$ & 1995Q1 \\
\hline GDP & 1.92 & 1.98 & 1.08 & 1.04 & 0.85 & $1980 Q 1$ & $1999 Q 2$ & 1995Q1 \\
\hline Output Gap & 1.75 & 1.78 & 0.83 & 0.78 & 0.89 & $1980 Q 1$ & $1999 Q 2$ & 1995Q1 \\
\hline$M 3$ & 1.02 & 1.07 & 1.30 & $1.27 \|$ & 1.07 & $1982 Q 3$ & $1999 Q 2$ & 1995Q1 \\
\hline \multicolumn{9}{|c|}{ Overall Factors, Balanced Panel } \\
\hline F1B & 1.03 & 1.05 & 1.00 & $0.97 \|$ & 0.75 & $1980 Q 1$ & $1999 Q 2$ & 1995Q1 \\
\hline$F 1 B$ to $F 2 B$ & 1.19 & 1.24 & 1.21 & 1.18 & 0.79 & $1980 Q 1$ & $1999 Q 2$ & 1995Q1 \\
\hline$F 1 B$ to $F 3 B$ & 1.24 & 1.33 & 1.35 & $1.24 \|$ & 1.01 & 1980Q1 & $1999 Q 2$ & 1995Q1 \\
\hline \multirow{2}{*}{\multicolumn{9}{|c|}{ Overall Factors, Unbalanced Panel }} \\
\hline F1U & & & & & 0.98 & $1980 Q 1$ & $1999 Q 2$ & 1995Q1 \\
\hline F1U to F2U & 1.05 & 1.15 & 1.20 & 1.19 & 0.89 & $1980 Q 1$ & $1999 Q 2$ & 1995Q1 \\
\hline F1U to F3U & 0.94 & 1.07 & 0.96 & $0.88 \|$ & 0.75 & $1980 Q 1$ & $1999 Q 2$ & 1995Q1 \\
\hline \multicolumn{9}{|c|}{ Nominal Factors, Balanced Panel } \\
\hline$F 1 B$ & 1.17 & 1.11 & 1.10 & $1.12 \|$ & 0.83 & $1980 Q 1$ & $1999 Q 2$ & 1995Q1 \\
\hline$F 1 B$ to $F 2 B$ & 1.01 & 1.03 & 1.02 & $1.02 \|$ & 0.48 & $1980 Q 1$ & $1999 Q 2$ & 1995Q1 \\
\hline$F 1 B$ to $F 3 B$ & 0.99 & 1.03 & 1.08 & $1.15 \|$ & 0.52 & $1980 Q 1$ & $1999 Q 2$ & 1995Q1 \\
\hline \multicolumn{9}{|c|}{ Nominal Factors, Unbalanced Panel } \\
\hline F1U & 1.17 & 1.13 & 1.16 & $1.18 \|$ & 0.89 & $1980 Q 1$ & $1999 Q 2$ & 1995Q1 \\
\hline F1U to & 1.05 & 1.05 & 1.03 & 1.05 & 0.56 & $1980 Q 1$ & $1999 Q 2$ & 1995Q1 \\
\hline F1U to F3U & 1.09 & 1.07 & 1.10 & $1.15 \|$ & 0.70 & 1980Q1 & $1999 Q 2$ & 1995Q1 \\
\hline \multicolumn{9}{|c|}{ Non-Nominal Factors, Balanced Panel } \\
\hline F1B & \begin{tabular}{|c|}
1.03 \\
\end{tabular} & 1.06 & 1.06 & 1.04|| & 0.83 & $1980 Q 1$ & 199902 & 1995Q1 \\
\hline$F 1 B$ to $F 2 B$ & 1.04 & 1.08 & 1.10 & 1.03 & 0.86 & $1980 Q 1$ & $1999 Q 2$ & 1995Q1 \\
\hline$F 1 B$ to $F 3 B$ & 1.03 & 1.13 & 1.32 & $1.17 \|$ & 1.21 & $1980 Q 1$ & $1999 Q 2$ & 1995Q1 \\
\hline \multirow{2}{*}{\multicolumn{9}{|c|}{ Non-Nominal Factors, Unbalanced Panel }} \\
\hline F1U & & & & & 0.94 & $1980 Q 1$ & $1999 Q 2$ & 1995Q1 \\
\hline F1u & 0.90 & 0.81 & 0.74 & 0.79 & 0.79 & $1980 Q 1$ & $1999 Q 2$ & 1995Q1 \\
\hline F1U to F3U & 0.85 & 0.71 & 0.73 & 0.57 & 0.57 & $1980 Q 1$ & $1999 Q 2$ & 1995Q1 \\
\hline
\end{tabular}

YED

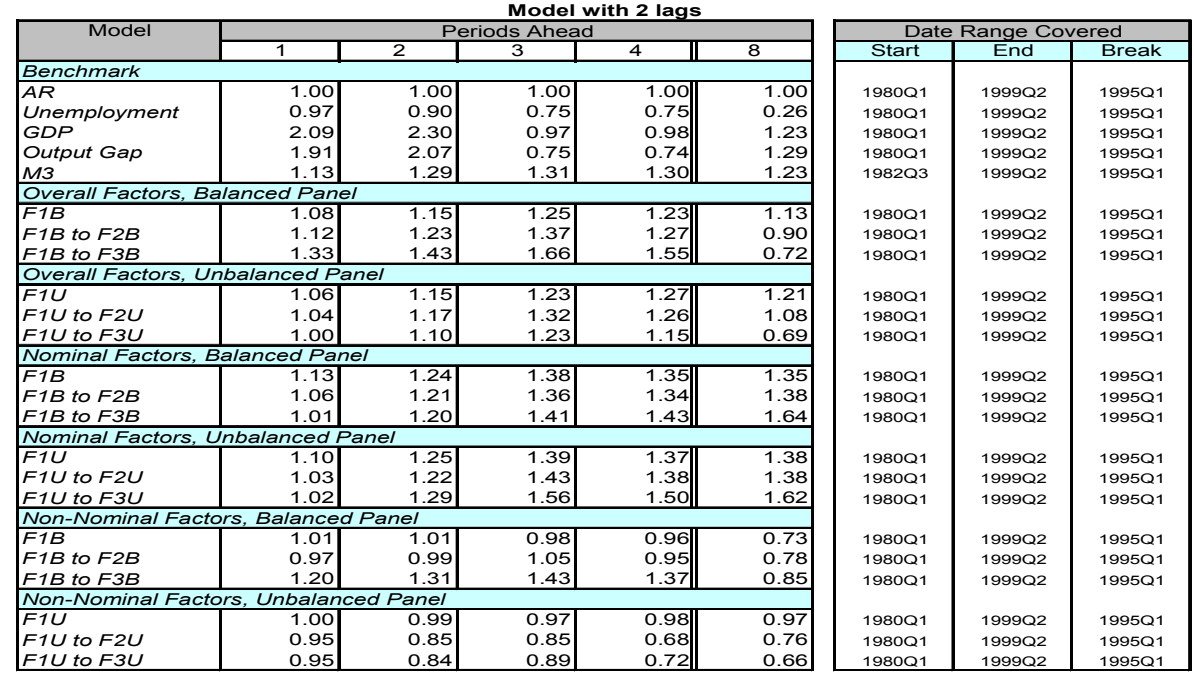


Table 2

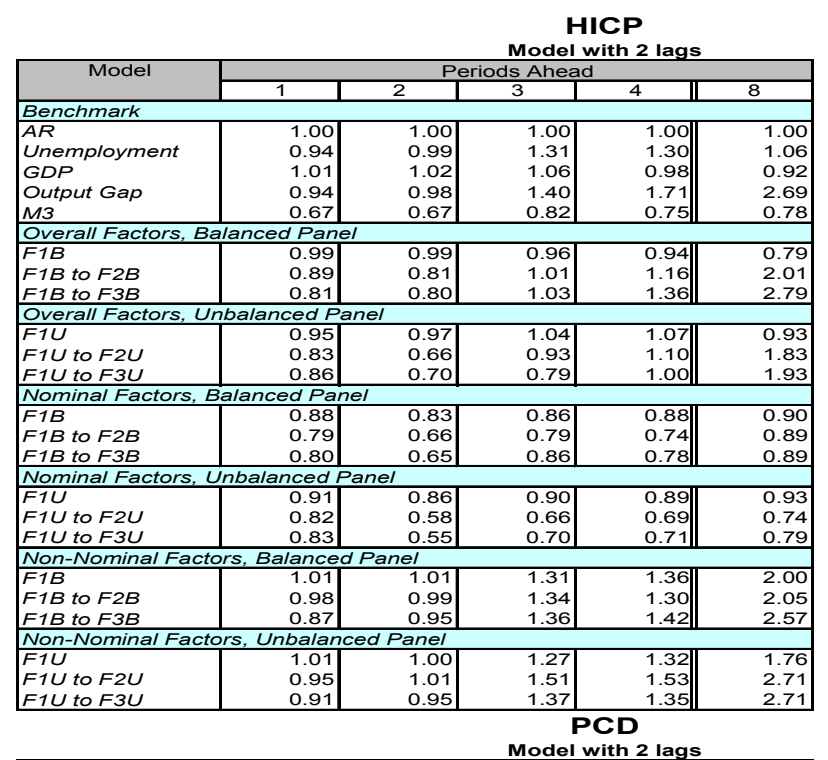

\begin{tabular}{|c|c|c|}
\hline \multicolumn{3}{|c|}{ Date Range Covered } \\
\hline Start & End & Break \\
\hline $1980 Q 1$ & $1999 Q 2$ & $1992 Q 1$ \\
$1980 Q 1$ & $1999 Q 2$ & $1992 Q 1$ \\
$1980 Q 1$ & $1999 Q 2$ & $1992 Q 1$ \\
$1980 Q 1$ & $1999 Q 2$ & $1992 Q 1$ \\
$1982 Q 3$ & $1999 Q 2$ & $1992 Q 1$ \\
& & \\
$1980 Q 1$ & $1999 Q 2$ & $1992 Q 1$ \\
$1980 Q 1$ & $1999 Q 2$ & $1992 Q 1$ \\
$1980 Q 1$ & $1999 Q 2$ & $1992 Q 1$ \\
& & \\
$1980 Q 1$ & $1999 Q 2$ & $1992 Q 1$ \\
$1980 Q 1$ & $1999 Q 2$ & $1992 Q 1$ \\
$1980 Q 1$ & $1999 Q 2$ & $1992 Q 1$ \\
& & \\
$1980 Q 1$ & $1999 Q 2$ & $1992 Q 1$ \\
$1980 Q 1$ & $1999 Q 2$ & $1992 Q 1$ \\
$1980 Q 1$ & $1999 Q 2$ & $1992 Q 1$ \\
& & \\
$1980 Q 1$ & $1999 Q 2$ & $1992 Q 1$ \\
$1980 Q 1$ & $1999 Q 2$ & $1992 Q 1$ \\
$1980 Q 1$ & $1999 Q 2$ & $1992 Q 1$ \\
$1980 Q 1$ & $1999 Q 2$ & $1992 Q 1$ \\
$1980 Q 1$ & $1999 Q 2$ & $1992 Q 1$ \\
$1980 Q 1$ & $1999 Q 2$ & $1992 Q 1$ \\
$1980 Q 1$ & $1999 Q 2$ & $1992 Q 1$ \\
$1980 Q 1$ & $1999 Q 2$ & $1992 Q 1$ \\
$1980 Q 1$ & $1999 Q 2$ & $1992 Q 1$ \\
\hline
\end{tabular}

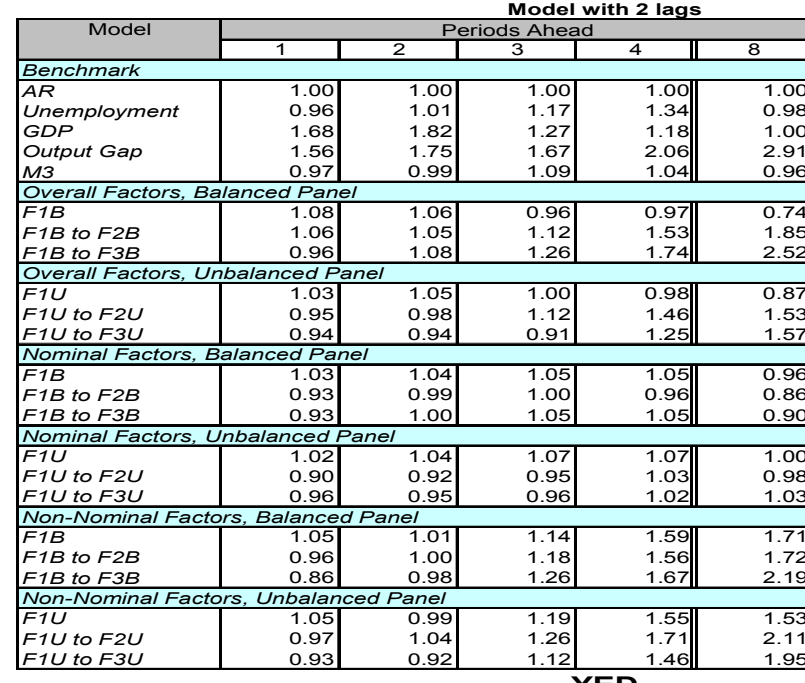

\begin{tabular}{|c|c|c|}
\hline \multicolumn{3}{|c|}{ Date Range Covered } \\
\hline Start & End & Break \\
\hline $1980 Q 1$ & $1999 Q 2$ & $1992 Q 1$ \\
$1980 Q 1$ & $1999 Q 2$ & $1992 Q 1$ \\
$1980 Q 1$ & $1999 Q 2$ & $192 Q 1$ \\
$1980 Q 1$ & $1999 Q 2$ & $1992 Q 1$ \\
$1982 Q 3$ & $1999 Q 2$ & $1992 Q 1$ \\
& & \\
$1980 Q 1$ & $1999 Q 2$ & $1992 Q 1$ \\
$1980 Q 1$ & $1999 Q 2$ & $192 Q 1$ \\
$1980 Q 1$ & $1999 Q 2$ & $1992 Q 1$ \\
& & \\
$1980 Q 1$ & $1999 Q 2$ & $1992 Q 1$ \\
$1980 Q 1$ & $1999 Q 2$ & $192 Q 1$ \\
$1980 Q 1$ & $1999 Q 2$ & $1992 Q 1$ \\
& & \\
$1980 Q 1$ & $1999 Q 2$ & $1992 Q 1$ \\
$1980 Q 1$ & $1999 Q 2$ & $1992 Q 1$ \\
$1980 Q 1$ & $1999 Q 2$ & $1992 Q 1$ \\
& & \\
$1980 Q 1$ & $1999 Q 2$ & $1992 Q 1$ \\
$1980 Q 1$ & $1999 Q 2$ & $1992 Q 1$ \\
$1980 Q 1$ & $1999 Q 2$ & $1992 Q 1$ \\
& & \\
$1980 Q 1$ & $1999 Q 2$ & $1992 Q 1$ \\
$1980 Q 1$ & $1999 Q 2$ & $1992 Q 1$ \\
$1980 Q 1$ & $1999 Q 2$ & $1992 Q 1$ \\
& & \\
$1980 Q 1$ & $1999 Q 2$ & $1992 Q 1$ \\
$1980 Q 1$ & $1999 Q 2$ & $1992 Q 1$ \\
$1980 Q 1$ & $1999 Q 2$ & $1992 Q 1$ \\
\hline
\end{tabular}

\begin{tabular}{|c|c|c|c|c|c|}
\hline & & & Model & h 2 lags & \\
\hline Model & & & Periods Ahea & & \\
\hline & 1 & 2 & 1 3 & 4 & 8 \\
\hline Benchmark & & & & & \\
\hline$A R$ & 1.00 & 1.00 & 1.00 & 1.00 & 1.00 \\
\hline Unemployment & 1.11 & 1.19 & 1.28 & 1.22 & 1.22 \\
\hline$G D P$ & 1.95 & 2.04 & 1.19 & $1.03 \|$ & 1.23 \\
\hline Output Gap & 1.82 & 1.96 & 1.56 & 1.80 & 3.58 \\
\hline & 1.10 & 1.14 & 1.19 & $1.14 \|$ & 1.11 \\
\hline Overall Factors, & alanced Pane & & & & \\
\hline F1B & 1.34 & 1.49 & 1.84 & $1.64 \|$ & 1.34 \\
\hline$F 1 B$ to $F 2 B$ & 1.19 & 1.22 & 1.40 & 1.08 & 2.10 \\
\hline F1B to $F 3 B$ & 1.17 & 1.23 & 1.42 & $1.18 \|$ & 2.05 \\
\hline Overall Factors, & nbalanced $P a$ & anel & & & \\
\hline F1U & 1.27 & 1.44 & 1.78 & $1.66 \|$ & 1.40 \\
\hline to $F 2 U$ & 1.12 & 1.14 & 1.30 & 1.03 & 1.95 \\
\hline F1U to F3U & 1.16 & 1.17 & 1.27 & 1.03 & 1.71 \\
\hline Nominal Factors & Balanced Pan & nel & & & \\
\hline$F 1 B$ & 1.11 & 1.19 & 1.36 & $1.31 \|$ & 1.30 \\
\hline$F 1 B$ to $F 2 B$ & 1.03 & 1.21 & 1.33 & 1.37 & 1.45 \\
\hline$F 1 B$ to $F 3 B$ & 1.09 & 1.24 & 1.37 & $1.36 \|$ & 1.32 \\
\hline Nominal Factors & Jnbalanced $P$ & Panel & & & \\
\hline F1L & 1.11 & 1.19 & 1.36 & $1.31 \mid$ & 1.32 \\
\hline to $F 2 U$ & 1.02 & 1.17 & 1.34 & 1.30 & 1.30 \\
\hline F1U to $F 3 U$ & 1.05 & 1.24 & 1.43 & $1.41 \|$ & 1.52 \\
\hline Non-Nominal F & ors, Balancec & d Panel & & & \\
\hline$F 1 B$ & 1.08 & 0.99 & 0.89 & $1.04 \|$ & 2.52 \\
\hline$F 1 B$ to $F 2 B$ & 1.20 & 1.21 & 1.31 & $1.12 \|$ & 2.08 \\
\hline F1B to $F 3 B$ & 1.19 & 1.20 & 1.36 & 1.29 & 2.13 \\
\hline & ibalanc & d Panel & & & \\
\hline F1U & 1.09 & 1.01 & 0.93 & 1.02 & 2.29 \\
\hline F1U to F2U & 0.98 & 0.88 & 0.86 & 0.95 & 2.34 \\
\hline F1U to F3U & 0.98 & 0.8 & 0.80 & $0.86 \|$ & 1.99 \\
\hline
\end{tabular}

\begin{tabular}{|c|c|c|}
\hline \multicolumn{3}{|c|}{ Date Range Covered } \\
\hline Start & End & Break \\
\hline $1980 Q 1$ & $1999 Q 2$ & $1992 Q 1$ \\
$1980 Q 1$ & $1999 Q 2$ & $1992 Q 1$ \\
$1980 Q 1$ & $1999 Q 2$ & $1992 Q 1$ \\
$1980 Q 1$ & $1999 Q 2$ & $1992 Q 1$ \\
$1982 Q 3$ & $1999 Q 2$ & $1992 Q 1$ \\
& & \\
$1980 Q 1$ & $1999 Q 2$ & $1992 Q 1$ \\
$1980 Q 1$ & $1999 Q 2$ & $1992 Q 1$ \\
$1980 Q 1$ & $1999 Q 2$ & $1992 Q 1$ \\
& & \\
$1980 Q 1$ & $1999 Q 2$ & $1992 Q 1$ \\
$1980 Q 1$ & $1999 Q 2$ & $1992 Q 1$ \\
$1980 Q 1$ & $1999 Q 2$ & $1992 Q 1$ \\
& & \\
$1980 Q 1$ & $1999 Q 2$ & $1992 Q 1$ \\
$1980 Q 1$ & $1999 Q 2$ & $1992 Q 1$ \\
$1980 Q 1$ & $1999 Q 2$ & $1992 Q 1$ \\
& & \\
$1980 Q 1$ & $1999 Q 2$ & $1992 Q 1$ \\
$1980 Q 1$ & $1999 Q 2$ & $1992 Q 1$ \\
$1980 Q 1$ & $1999 Q 2$ & $1992 Q 1$ \\
& & \\
$1980 Q 1$ & $1999 Q 2$ & $1992 Q 1$ \\
$1980 Q 1$ & $1999 Q 2$ & $1992 Q 1$ \\
$1980 Q 1$ & $1999 Q 2$ & $1992 Q 1$ \\
& & \\
$1980 Q 1$ & $1999 Q 2$ & $1992 Q 1$ \\
$1980 Q 1$ & $1999 Q 2$ & $1992 Q 1$ \\
$1980 Q 1$ & $1999 Q 2$ & $1992 Q 1$ \\
\hline \multicolumn{3}{|c}{}
\end{tabular}


Table 3

HICP

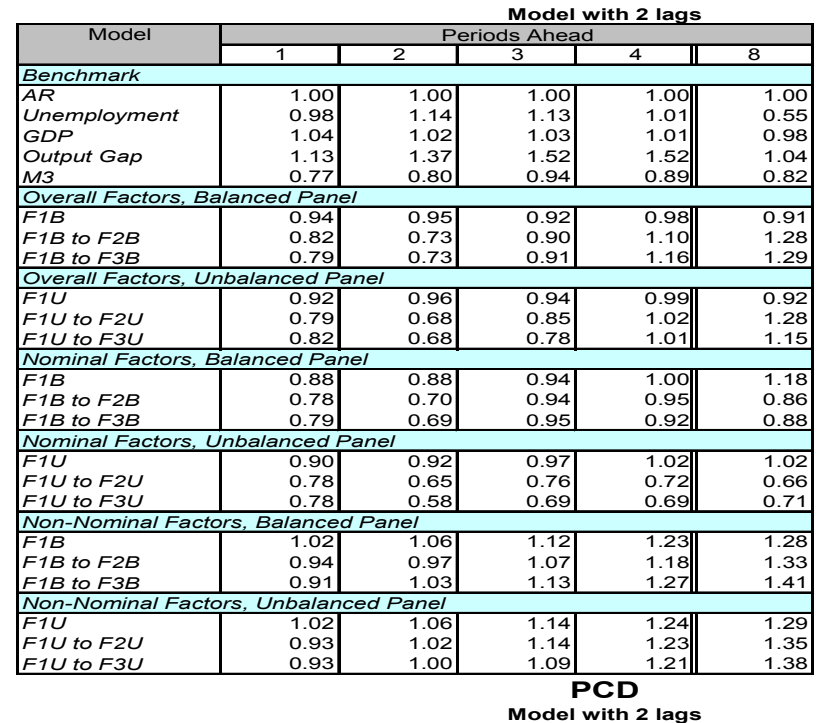

\begin{tabular}{|c|c|c|}
\hline \multicolumn{3}{|c|}{ Date Range Covered } \\
\hline Start & End & Break \\
\hline 1980Q1 & 1999Q2 & 1985Q1 \\
\hline 1980Q1 & 1999Q2 & 1985Q1 \\
\hline $1980 Q 1$ & 1999Q2 & 1985Q1 \\
\hline 1980Q1 & 1999Q2 & 1985Q1 \\
\hline $1982 Q 3$ & 1999Q2 & 1985Q1 \\
\hline 1980Q1 & $1999 Q 2$ & 1985Q1 \\
\hline 1980Q1 & $1999 Q 2$ & 1985Q1 \\
\hline 1980Q1 & 1999Q2 & 1985Q1 \\
\hline 1980Q1 & $1999 Q 2$ & $1985 Q 1$ \\
\hline $1980 Q 1$ & $1999 Q 2$ & $1985 Q 1$ \\
\hline 1980Q1 & 1999Q2 & 1985Q1 \\
\hline 1980Q1 & 1999Q2 & 1985Q1 \\
\hline $1980 Q 1$ & $1999 Q 2$ & $1985 Q 1$ \\
\hline 1980Q1 & 1999Q2 & 1985Q1 \\
\hline $1980 Q 1$ & $1999 Q 2$ & $1985 Q 1$ \\
\hline $1980 Q 1$ & $1999 Q 2$ & 1985Q1 \\
\hline 1980Q1 & 1999Q2 & 1985Q1 \\
\hline $1980 Q 1$ & $1999 Q 2$ & 1985Q1 \\
\hline 1980Q1 & 1999Q2 & 1985Q1 \\
\hline 1980Q1 & 1999Q2 & 1985Q1 \\
\hline $1980 Q 1$ & $1999 Q 2$ & $1985 Q 1$ \\
\hline $1980 Q 1$ & $1999 Q 2$ & 1985Q1 \\
\hline $1980 Q 1$ & $1999 Q 2$ & $1985 Q 1$ \\
\hline
\end{tabular}

\begin{tabular}{|c|c|c|c|c|c|}
\hline \multirow{4}{*}{\begin{tabular}{|c|} 
Model \\
Benchmark
\end{tabular}} & \multirow{2}{*}{\multicolumn{5}{|c|}{$\begin{array}{c}\text { Model with } \\
\text { Periods Ahead }\end{array}$}} \\
\hline & & & & & \\
\hline & 1 & 2 & 3 & 4 & 8 \\
\hline & \\
\hline$A R$ & 1.00 & 1.00 & 1.00 & 1.00 & 1.00 \\
\hline Unemployment & 1.04 & 1.04 & 1.06 & 0.98 & 0.54 \\
\hline$G D P$ & 1.56 & 1.44 & 1.10 & 1.05 & 1.04 \\
\hline Output Gap & 1.69 & 1.93 & 1.62 & $1.58 \|$ & 1.11 \\
\hline & 1.01 & 1.00 & 0.97 & $0.96 \|$ & 0.72 \\
\hline \multicolumn{6}{|l|}{ Overall Factors } \\
\hline$F 1 B$ & 1.05 & 1.01 & $0.97 \mid$ & $1.10 \|$ & 1.19 \\
\hline$F 1 B$ to $F 2 B$ & 1.02 & 1.02 & 1.02 & $1.24 \|$ & 1.62 \\
\hline F1B to $F 3 B$ & 1.04 & 1.07 & 1.04 & 1.33\| & 1.54 \\
\hline \multicolumn{6}{|c|}{ Overall Factors, Unbalanced Panel } \\
\hline F1U & 1.04 & 1.00 & 1.00 & $1.12 \|$ & 1.14 \\
\hline$F 1 U$ to $F 2 U$ & 0.99 & 1.00 & 1.05 & 1.22 & 1.65 \\
\hline F1U to F3U & 1.05 & 0.98 & 0.94 & $1.16 \|$ & 1.41 \\
\hline \multicolumn{6}{|c|}{ Balanced Panel } \\
\hline F1B & 1.05 & 1.03 & 0.98 & $1.04 \|$ & 1.16 \\
\hline$F 1 B$ to $F 2 B$ & 0.94 & 0.99 & 0.96 & $1.04 \|$ & 0.99 \\
\hline F1B to $F 3 B$ & 0.94 & 0.96 & 1.02 & $1.08 \|$ & 0.81 \\
\hline \multicolumn{6}{|c|}{ Nominal Factors, Unbalanced Panel } \\
\hline F1U & 1.06 & 1.04 & 1.02 & 1.10 & 1.08 \\
\hline F1U to F2U & 0.91 & 0.90 & 0.89 & $0.86 \|$ & 0.82 \\
\hline F1U to F3U & 0.92 & 0.90 & 0.90 & $0.84 \|$ & 0.80 \\
\hline \multirow{2}{*}{\multicolumn{6}{|c|}{ Non-Nominal Factors, Balanced Panel }} \\
\hline & & 1.02 & 1.04 & 1.2 & 1.66 \\
\hline$F 1 B$ to $F 2 B$ & 0.98 & 1.00 & 1.04 & $1.28 \|$ & 1.79 \\
\hline F1B to $F 3 B$ & 1.01 & 1.05 & 1.11 & $1.40 \|$ & 1.75 \\
\hline \multicolumn{6}{|c|}{ Non-Nominal Factors, Unbalanced Panel } \\
\hline F1U & 1.06 & 1.02 & 1.6 & $1.27 \|$ & 1.71 \\
\hline$F 1 \cup t$ & 1.03 & 1.00 & 1.13 & $1.29 \|$ & 1.79 \\
\hline F1U to & 1.05 & 1.00 & 1.06 & $1.28 \|$ & 1.68 \\
\hline
\end{tabular}

\begin{tabular}{|c|c|c|}
\hline \multicolumn{3}{|c|}{ Date Range Covered } \\
\hline Start & End & Break \\
\hline 1980Q1 & $1999 Q 2$ & $1985 Q 1$ \\
$1880 Q 1$ & $1999 Q 2$ & $1985 Q 1$ \\
$1980 Q 1$ & $1999 Q 2$ & $1985 Q 1$ \\
1980Q1 & $1999 Q 2$ & $1985 Q 1$ \\
1982Q3 & $1999 Q 2$ & $1985 Q 1$ \\
& & \\
1980Q1 & $1999 Q 2$ & $1985 Q 1$ \\
1980Q1 & $1999 Q 2$ & $1985 Q 1$ \\
1980Q1 & $1999 Q 2$ & $1985 Q 1$ \\
& & \\
1980Q1 & $1999 Q 2$ & $1985 Q 1$ \\
1980Q1 & $1999 Q 2$ & $1985 Q 1$ \\
1980Q1 & $1999 Q 2$ & $1985 Q 1$ \\
& & \\
1980Q1 & $1999 Q 2$ & $1985 Q 1$ \\
1980Q1 & $1999 Q 2$ & $1985 Q 1$ \\
1980Q1 & $1999 Q 2$ & $1985 Q 1$ \\
& & \\
1980Q1 & $1999 Q 2$ & $1985 Q 1$ \\
1980Q1 & $1999 Q 2$ & $1985 Q 1$ \\
1980Q1 & $1999 Q 2$ & $1985 Q 1$ \\
& & \\
1980Q1 & $1999 Q 2$ & $1985 Q 1$ \\
1980Q1 & $1999 Q 2$ & $1985 Q 1$ \\
1980Q1 & $1999 Q 2$ & $1985 Q 1$ \\
1980Q1 & $1999 Q 2$ & $1985 Q 1$ \\
$1980 Q 1$ & $1999 Q 2$ & $1985 Q 1$ \\
$1980 Q 1$ & $1999 Q 2$ & $1985 Q 1$ \\
\hline \multicolumn{2}{|c}{}
\end{tabular}

YED

\begin{tabular}{|c|c|c|c|c|c|}
\hline Model & & & Periods Ahea & & \\
\hline & 1 & 2 & 3 & 4 & 8 \\
\hline Benchmark & & & & & \\
\hline$A R$ & 1.00 & 1.00 & 1.00 & $1.00 \|$ & 1.00 \\
\hline Unemployment & 1.03 & 1.16 & 1.24 & 1.03 & 0.54 \\
\hline GDP & 1.55 & 1.64 & 1.23 & 1.11 & 1.38 \\
\hline Output Gap & 1.68 & 2.21 & 1.80 & 1.66 & 1.47 \\
\hline & 1.09 & 1.07 & 1.04 & 0.97 & 2.70 \\
\hline Overall Factors, & Ianced Pant & & & & \\
\hline F1B & 0.99 & 1.02 & 1.13 & $1.05 \mid$ & 0.74 \\
\hline$F 1 B$ to $F 2 B$ & 1.01 & 1.06 & 1.04 & 0.89 & 1.16 \\
\hline F1B to $F 3 B$ & 1.05 & 1.13 & 1.09 & 0.94 & 1.06 \\
\hline Overall Factors, & balanced $P$ & anel & & & \\
\hline F1U & 0.97 & 1.00 & 1.12 & 1.02 & 0.75 \\
\hline F1U to F2U & 0.98 & 1.03 & 1.05 & 0.84 & 0.99 \\
\hline F1U to F3U & 1.07 & 1.11 & 1.08 & 0.89 & 0.89 \\
\hline Nominal Factors & alanced Par & & & & \\
\hline F1B & 1.00 & 1.01 & 1.01 & $1.02 \mid$ & 0.67 \\
\hline$F 1 B$ to $F 2 B$ & 0.98 & 1.04 & 1.01 & 1.09 & 0.79 \\
\hline F1B to $F 3 B$ & 1.00 & 1.07 & 1.08 & 1.12 & 0.74 \\
\hline$N$ & Inbalanced $f$ & Panel & & & \\
\hline F1U & 0.98 & 1.02 & 1.06 & 1.03 & 0.63 \\
\hline F1U to F2U & 0.96 & 1.04 & 0.99 & 1.03 & 0.69 \\
\hline F1U to F3U & 1.00 & 1.1 & 1.13 & 1.16 & 0.65 \\
\hline Non-Nominal Fa & ors, Balanced & d Panel & & & \\
\hline$F 1 B$ & 1.03 & 1.03 & 1.04 & $0.97 \|$ & 1.11 \\
\hline$F 1 B$ to $F 2 B$ & 1.00 & 1.04 & 1.04 & $0.88 \|$ & 1.06 \\
\hline$F 1 B$ to $F 3 B$ & 1.01 & 1.05 & 1.06 & 0.92 & 0.89 \\
\hline omina & Unt & $e d t$ & & & \\
\hline F1U & 1.03 & 1.05 & 1.07 & $1.00 \|$ & 0.98 \\
\hline$F 1 U$ to $F 2 U$ & 0.91 & 0.9 & 0.5 & $0.81 \|$ & 0.96 \\
\hline F1U to F3U & 0.93 & 0.90 & 0.88 & 0.82 & 0.78 \\
\hline
\end{tabular}

\begin{tabular}{|c|c|c|}
\hline \multicolumn{3}{|c|}{ Date Range Covered } \\
\hline Start & End & Break \\
\hline $1980 Q 1$ & $1999 Q 2$ & $1985 Q 1$ \\
$1980 Q 1$ & $1999 Q 2$ & $1985 Q 1$ \\
$1980 Q 1$ & $1999 Q 2$ & $1985 Q 1$ \\
$1980 Q 1$ & $1999 Q 2$ & $1985 Q 1$ \\
$1982 Q 3$ & $1999 Q 2$ & $1985 Q 1$ \\
& & \\
$1980 Q 1$ & $1999 Q 2$ & $1985 Q 1$ \\
$1980 Q 1$ & $1999 Q 2$ & $1985 Q 1$ \\
$1980 Q 1$ & $1999 Q 2$ & $1985 Q 1$ \\
& & \\
$1980 Q 1$ & $1999 Q 2$ & $1985 Q 1$ \\
$1980 Q 1$ & $1999 Q 2$ & $1985 Q 1$ \\
$1980 Q 1$ & $1999 Q 2$ & $1985 Q 1$ \\
& & \\
$1980 Q 1$ & $1999 Q 2$ & $1985 Q 1$ \\
$1980 Q 1$ & $1999 Q 2$ & $1985 Q 1$ \\
$1980 Q 1$ & $1999 Q 2$ & $1985 Q 1$ \\
& & \\
$1980 Q 1$ & $1999 Q 2$ & $1985 Q 1$ \\
$1980 Q 1$ & $1999 Q 2$ & $1985 Q 1$ \\
$1980 Q 1$ & $1999 Q 2$ & $1985 Q 1$ \\
& & \\
$1980 Q 1$ & $1999 Q 2$ & $1985 Q 1$ \\
$1980 Q 1$ & $1999 Q 2$ & $1985 Q 1$ \\
$1980 Q 1$ & $1999 Q 2$ & $1985 Q 1$ \\
& & \\
$1980 Q 1$ & $1999 Q 2$ & $1985 Q 1$ \\
$1980 Q 1$ & $1999 Q 2$ & $1985 Q 1$ \\
$1980 Q 1$ & $1999 Q 2$ & $1985 Q 1$ \\
\hline
\end{tabular}




\section{References}

Angelini, E., J. Henry and R. Mestre (2001), “A multi-country trend indicator for euro area average inflation: computation and properties", European Central Bank Working Paper Series, No. 60.

Bai, J., S. Ng (2000), "Determining the Number of Factors in Approximate Factor Models", mimeo.

Bernanke, B.S. (2000), "Monetary Policy in a Data-Rich Environment", mimeo.

Forni, M., M. Hallin, M. Lippi and L. Reichlin (1999), "The Generalized Dynamic Factor Model: Identification and Estimation”, CEPR Discussion Paper No. 2338.

Forni, M., and M. Lippi (2000), “The Generalized Dynamic Factor Model: Representaion Theory”, CEPR Discussion Paper No. 2509.

Forni, M., and L. Reichlin (1998), "Let's Get Real: A Factor Analytical Approach to Disaggregated Business Cycle Dynamics", Review of Economic Studies, 65(3), July 1998, pages 453-73.

Clements, M.P. and D.F. Hendry (1998), Forecasting economic time series, Cambridge; New York and Melbourne: Cambridge University Press, 1998, pages xxi, 368.

Marcellino, M. , J.H. Stock, and Mark W. Watson (2000), "Macroeconomic Forecasting in the Euro Area: Country Specific versus Area-Wide Information", mimeo.

Nicoletti-Altimari, S. (2001), "The Leading-indicator Properties of Monetary Aggregates in the euro Area”, European Central Bank Working Paper Series, forthcoming.

Quah, D and T.J. Sargent (1993), “A Dynamic Index Model for Large Cross Sections”, Business Cycles, Indicators, and Forecasting, chapter 7, J.H. Stock and M.W. Watson eds., NBER and University of Chicago Press.

Sargent, T.J. and C.A. Sims (1977), "Business Cycle Modelling without Pretending to Have Too Much a-priori Economic Theory", New Methods in Business Cycle Research, C. Sims et al (eds.), Minneapolis: Federal Reserve Bank of Minneapolis.

Stock, J.H., and M.W. Watson (1998), "Diffusion Indexes", NBER Working Paper \#6702. 
Stock, J.H. and M.W. Watson (1999), "Forecasting Inflation", Journal of Monetary economics 44, 293-335. 


\section{Appendix A. Loadings}

Table 1. Balanced Panel

\begin{tabular}{|c|c|c|c|c|c|c|c|c|c|c|}
\hline Variable & & & oading & & & & & igs Sc & & \\
\hline & F1 & F2 & F3 & F4 & F5 & F1 & F2 & F3 & F4 & F5 \\
\hline CPIAT & 0.73 & -0.11 & 0.22 & -0.09 & -0.18 & 0.53 & 0.01 & 0.05 & 0.01 & 0.03 \\
\hline CPIBE & 0.84 & -0.03 & -0.08 & 0.05 & 0.09 & 0.70 & 0.00 & 0.01 & 0.00 & 0.01 \\
\hline CPIDE & 0.69 & -0.06 & 0.44 & -0.15 & 0.02 & 0.47 & 0.00 & 0.19 & 0.02 & 0.00 \\
\hline CPIES & 0.82 & -0.15 & -0.25 & 0.20 & -0.19 & 0.67 & 0.02 & 0.06 & 0.04 & 0.04 \\
\hline CPIFI & 0.78 & -0.31 & -0.05 & 0.32 & 0.04 & 0.61 & 0.09 & 0.00 & 0.10 & 0.00 \\
\hline CPIFR & 0.92 & -0.20 & -0.17 & 0.15 & 0.01 & 0.84 & 0.04 & 0.03 & 0.02 & 0.00 \\
\hline CPIIE & 0.83 & -0.20 & -0.03 & 0.20 & 0.15 & 0.68 & 0.04 & 0.00 & 0.04 & 0.02 \\
\hline CPIIT & 0.90 & -0.20 & -0.13 & 0.15 & 0.03 & 0.80 & 0.04 & 0.02 & 0.02 & 0.00 \\
\hline CPINL & 0.75 & -0.13 & 0.16 & -0.12 & -0.07 & 0.56 & 0.02 & 0.03 & 0.01 & 0.01 \\
\hline CPIPT & 0.70 & -0.12 & -0.31 & 0.15 & -0.23 & 0.48 & 0.01 & 0.10 & 0.02 & 0.06 \\
\hline MTDAT & 0.45 & -0.34 & 0.23 & -0.29 & 0.12 & 0.20 & 0.12 & 0.05 & 0.08 & 0.01 \\
\hline MTDDE & 0.54 & -0.44 & 0.20 & -0.40 & 0.19 & 0.29 & 0.19 & 0.04 & 0.16 & 0.04 \\
\hline MTDES & 0.75 & -0.15 & 0.11 & -0.18 & 0.29 & 0.56 & 0.02 & 0.01 & 0.03 & 0.09 \\
\hline MTDFI & 0.54 & -0.18 & 0.24 & -0.19 & 0.04 & 0.29 & 0.03 & 0.06 & 0.04 & 0.00 \\
\hline MTDFR & 0.64 & -0.39 & -0.01 & -0.29 & 0.24 & 0.41 & 0.15 & 0.00 & 0.09 & 0.06 \\
\hline MTDIT & 0.64 & -0.21 & 0.24 & -0.36 & 0.25 & 0.41 & 0.05 & 0.06 & 0.13 & 0.06 \\
\hline PCDAT & 0.74 & -0.05 & 0.12 & -0.10 & -0.18 & 0.55 & 0.00 & 0.02 & 0.01 & 0.03 \\
\hline PCDDE & 0.66 & -0.11 & 0.42 & -0.09 & 0.12 & 0.43 & 0.01 & 0.18 & 0.01 & 0.01 \\
\hline PCDES & 0.80 & -0.09 & -0.22 & 0.27 & -0.18 & 0.63 & 0.01 & 0.05 & 0.07 & 0.03 \\
\hline PCDFR & 0.91 & -0.18 & -0.20 & 0.14 & 0.00 & 0.82 & 0.03 & 0.04 & 0.02 & 0.00 \\
\hline PCDIT & 0.92 & -0.18 & -0.14 & 0.15 & 0.03 & 0.84 & 0.03 & 0.02 & 0.02 & 0.00 \\
\hline PCDFI & 0.79 & -0.16 & 0.01 & 0.26 & -0.05 & 0.62 & 0.03 & 0.00 & 0.07 & 0.00 \\
\hline PPIAT & 0.58 & -0.40 & 0.18 & -0.19 & 0.04 & 0.34 & 0.16 & 0.03 & 0.04 & 0.00 \\
\hline PPIDE & 0.68 & -0.51 & 0.15 & -0.25 & 0.11 & 0.46 & 0.26 & 0.02 & 0.06 & 0.01 \\
\hline PPIES & 0.85 & -0.20 & -0.24 & -0.08 & -0.01 & 0.72 & 0.04 & 0.06 & 0.01 & 0.00 \\
\hline PPIFI & 0.76 & -0.36 & 0.11 & -0.16 & 0.17 & 0.58 & 0.13 & 0.01 & 0.03 & 0.03 \\
\hline PPIFR & 0.72 & -0.34 & -0.32 & -0.08 & 0.12 & 0.52 & 0.12 & 0.10 & 0.01 & 0.01 \\
\hline PPINL & 0.64 & -0.43 & 0.14 & -0.34 & 0.05 & 0.40 & 0.18 & 0.02 & 0.12 & 0.00 \\
\hline XTDAT & 0.62 & -0.40 & 0.03 & -0.32 & 0.01 & 0.39 & 0.16 & 0.00 & 0.10 & 0.00 \\
\hline XTDDE & 0.71 & -0.43 & 0.07 & -0.26 & 0.12 & 0.51 & 0.18 & 0.00 & 0.07 & 0.01 \\
\hline XTDES & 0.88 & -0.05 & -0.13 & -0.05 & 0.15 & 0.78 & 0.00 & 0.02 & 0.00 & 0.02 \\
\hline XTDFI & 0.54 & -0.19 & 0.04 & -0.19 & -0.06 & 0.29 & 0.04 & 0.00 & 0.04 & 0.00 \\
\hline XTDFR & 0.77 & -0.24 & -0.24 & -0.16 & 0.23 & 0.59 & 0.06 & 0.06 & 0.03 & 0.06 \\
\hline XTDIT & 0.73 & -0.23 & 0.11 & -0.12 & 0.16 & 0.54 & 0.05 & 0.01 & 0.01 & 0.02 \\
\hline YEDAT & 0.55 & 0.03 & -0.04 & 0.16 & -0.33 & 0.30 & 0.00 & 0.00 & 0.02 & 0.11 \\
\hline YEDDE & 0.44 & 0.02 & 0.23 & 0.31 & -0.25 & 0.20 & 0.00 & 0.05 & 0.09 & 0.06 \\
\hline YEDES & 0.71 & -0.12 & -0.32 & 0.29 & -0.29 & 0.51 & 0.01 & 0.10 & 0.08 & 0.09 \\
\hline YEDFI & 0.57 & -0.19 & -0.15 & 0.27 & 0.14 & 0.33 & 0.04 & 0.02 & 0.07 & 0.02 \\
\hline YEDFR & 0.83 & -0.07 & -0.27 & 0.25 & -0.03 & 0.70 & 0.01 & 0.07 & 0.06 & 0.00 \\
\hline YEDIT & 0.88 & -0.23 & -0.16 & 0.21 & -0.01 & 0.77 & 0.05 & 0.03 & 0.04 & 0.00 \\
\hline CAPDE & -0.50 & $\begin{array}{l}-0.50 \\
\end{array}$ & 0.43 & 0.32 & -0.24 & 0.25 & 0.25 & 0.18 & 0.10 & 0.06 \\
\hline CAPES & 0.06 & -0.62 & -0.40 & 0.42 & 0.17 & 0.00 & 0.38 & 0.16 & 0.18 & 0.03 \\
\hline CAPFR & -0.28 & -0.46 & 0.32 & 0.39 & -0.25 & 0.08 & 0.21 & 0.10 & 0.15 & 0.06 \\
\hline CAPIT & -0.62 & -0.45 & 0.39 & 0.11 & 0.01 & 0.38 & 0.20 & 0.15 & 0.01 & 0.00 \\
\hline CAPNL & -0.79 & -0.35 & 0.33 & 0.06 & -0.09 & 0.62 & 0.12 & 0.11 & 0.00 & 0.01 \\
\hline CAPPT & -0.39 & -0.54 & 0.15 & 0.22 & 0.17 & 0.15 & 0.29 & 0.02 & 0.05 & 0.03 \\
\hline ERNAT & 0.37 & -0.08 & 0.21 & 0.31 & -0.15 & 0.14 & 0.01 & 0.04 & 0.10 & 0.02 \\
\hline ERNDE & 0.23 & -0.07 & 0.25 & 0.17 & -0.08 & 0.05 & 0.01 & 0.06 & 0.03 & 0.01 \\
\hline ERNES & 0.54 & -0.07 & 0.00 & 0.16 & -0.04 & 0.29 & 0.00 & 0.00 & 0.03 & 0.00 \\
\hline ERNFI & 0.31 & -0.28 & -0.12 & 0.12 & 0.06 & 0.10 & 0.08 & 0.01 & 0.02 & 0.00 \\
\hline ERNFR & 0.85 & -0.12 & -0.22 & 0.27 & -0.02 & 0.72 & 0.01 & 0.05 & 0.07 & 0.00 \\
\hline ERNIT & 0.82 & -0.13 & -0.17 & 0.21 & -0.03 & 0.68 & 0.02 & 0.03 & 0.04 & 0.00 \\
\hline ERNNL & 0.34 & 0.04 & 0.00 & 0.08 & -0.04 & 0.12 & 0.00 & 0.00 & 0.01 & 0.00 \\
\hline
\end{tabular}


Table 1. Balanced Panel (cont.)

\begin{tabular}{|c|c|c|c|c|c|c|c|c|c|c|}
\hline Variable & & & -oading & & & & & igs Sc & & \\
\hline & F1 & F2 & F3 & F4 & F5 & $\mathrm{F} 1$ & $\bar{F} 2$ & F3 & $\overline{F 4}$ & F5 \\
\hline GDPAT & -0.09 & -0.36 & -0.22 & -0.26 & -0.27 & 0.01 & 0.13 & 0.05 & 0.07 & 0.07 \\
\hline GDPDE & -0.12 & -0.30 & -0.39 & -0.20 & -0.52 & 0.01 & 0.09 & 0.15 & 0.04 & 0.27 \\
\hline GDPES & -0.55 & -0.36 & -0.27 & 0.05 & 0.28 & 0.31 & 0.13 & 0.07 & 0.00 & 0.08 \\
\hline GDPFI & -0.02 & -0.21 & -0.44 & -0.17 & 0.28 & 0.00 & 0.04 & 0.19 & 0.03 & 0.08 \\
\hline GDPFR & -0.17 & -0.46 & -0.49 & -0.13 & -0.12 & 0.03 & 0.22 & 0.24 & 0.02 & 0.01 \\
\hline GDPIT & 0.03 & -0.42 & -0.33 & -0.11 & -0.17 & 0.00 & 0.18 & 0.11 & 0.01 & 0.03 \\
\hline GDPNL & -0.29 & -0.19 & -0.14 & -0.14 & -0.18 & 0.09 & 0.03 & 0.02 & 0.02 & 0.03 \\
\hline HSTBE & -0.22 & -0.16 & -0.12 & -0.37 & -0.10 & 0.05 & 0.03 & 0.01 & 0.14 & 0.01 \\
\hline HSTES & -0.14 & 0.02 & -0.12 & -0.11 & 0.11 & 0.02 & 0.00 & 0.02 & 0.01 & 0.01 \\
\hline HSTFI & -0.08 & -0.38 & -0.19 & 0.18 & 0.35 & 0.01 & 0.15 & 0.03 & 0.03 & 0.12 \\
\hline HSTFR & -0.20 & 0.02 & -0.24 & -0.17 & 0.06 & 0.04 & 0.00 & 0.06 & 0.03 & 0.00 \\
\hline HSTNL & 0.04 & -0.07 & -0.11 & -0.15 & -0.07 & 0.00 & 0.00 & 0.01 & 0.02 & 0.00 \\
\hline LFNES & -0.27 & 0.04 & -0.12 & -0.12 & 0.16 & 0.07 & 0.00 & 0.01 & 0.01 & 0.02 \\
\hline LFNFI & 0.12 & -0.15 & -0.11 & -0.01 & 0.30 & 0.01 & 0.02 & 0.01 & 0.00 & 0.09 \\
\hline LFNFR & -0.07 & -0.12 & 0.26 & -0.08 & -0.33 & 0.00 & 0.01 & 0.07 & 0.01 & 0.11 \\
\hline LFNIT & 0.02 & -0.22 & -0.20 & 0.26 & 0.07 & 0.00 & 0.05 & 0.04 & 0.07 & 0.00 \\
\hline LFNNL & 0.24 & -0.22 & 0.24 & 0.16 & 0.26 & 0.06 & 0.05 & 0.06 & 0.02 & 0.07 \\
\hline LNNAT & -0.02 & -0.09 & 0.09 & -0.10 & -0.29 & 0.00 & 0.01 & 0.01 & 0.01 & 0.08 \\
\hline LNNBE & -0.58 & -0.43 & -0.22 & 0.10 & 0.11 & 0.34 & 0.18 & 0.05 & 0.01 & 0.01 \\
\hline LNNDE & -0.10 & -0.61 & -0.07 & 0.36 & -0.25 & 0.01 & 0.37 & 0.00 & 0.13 & 0.06 \\
\hline LNNES & -0.73 & -0.30 & -0.23 & 0.13 & 0.27 & 0.54 & 0.09 & 0.05 & 0.02 & 0.07 \\
\hline LNNFI & 0.03 & -0.51 & -0.43 & -0.11 & 0.47 & 0.00 & 0.26 & 0.18 & 0.01 & 0.22 \\
\hline LNNFR & -0.56 & -0.49 & -0.03 & 0.15 & 0.14 & 0.31 & 0.24 & 0.00 & 0.02 & 0.02 \\
\hline LNNIE & -0.50 & -0.18 & 0.01 & -0.01 & 0.13 & 0.25 & 0.03 & 0.00 & 0.00 & 0.02 \\
\hline LNNIT & -0.03 & -0.31 & -0.14 & 0.39 & 0.08 & 0.00 & 0.10 & 0.02 & 0.15 & 0.01 \\
\hline LNNPT & -0.24 & -0.49 & 0.08 & 0.16 & -0.10 & 0.06 & 0.24 & 0.01 & 0.03 & 0.01 \\
\hline LTIAT & 0.16 & -0.59 & 0.35 & -0.07 & -0.12 & 0.03 & 0.34 & 0.12 & 0.00 & 0.01 \\
\hline LTIBE & 0.36 & -0.59 & 0.29 & -0.21 & -0.02 & 0.13 & 0.34 & 0.08 & 0.04 & 0.00 \\
\hline LTIDE & 0.22 & -0.61 & 0.20 & -0.15 & -0.12 & 0.05 & 0.37 & 0.04 & 0.02 & 0.01 \\
\hline LTIFI & 0.21 & -0.50 & 0.10 & 0.04 & 0.06 & 0.05 & 0.25 & 0.01 & 0.00 & 0.00 \\
\hline LTIFR & 0.29 & -0.54 & 0.32 & -0.17 & 0.04 & 0.09 & 0.29 & 0.11 & 0.03 & 0.00 \\
\hline LTIIE & 0.25 & -0.39 & 0.24 & -0.20 & -0.22 & 0.06 & 0.15 & 0.06 & 0.04 & 0.05 \\
\hline LTIIT & 0.26 & -0.47 & 0.32 & -0.03 & 0.10 & 0.07 & 0.22 & 0.10 & 0.00 & 0.01 \\
\hline LTINL & 0.14 & -0.67 & 0.26 & -0.20 & -0.14 & 0.02 & 0.44 & 0.07 & 0.04 & 0.02 \\
\hline MFBBE & -0.61 & -0.59 & 0.17 & 0.09 & 0.14 & 0.37 & 0.34 & 0.03 & 0.01 & 0.02 \\
\hline MFBDE & -0.38 & -0.67 & 0.21 & 0.39 & -0.20 & 0.14 & 0.44 & 0.04 & 0.15 & 0.04 \\
\hline MFBFR & -0.48 & -0.72 & -0.05 & 0.21 & 0.26 & 0.23 & 0.51 & 0.00 & 0.04 & 0.07 \\
\hline MFBIE & -0.61 & -0.42 & 0.06 & -0.16 & -0.03 & 0.38 & 0.18 & 0.00 & 0.03 & 0.00 \\
\hline MFBIT & -0.59 & -0.66 & 0.19 & -0.04 & 0.11 & 0.34 & 0.44 & 0.04 & 0.00 & 0.01 \\
\hline MFBNL & -0.76 & -0.44 & 0.22 & -0.03 & -0.02 & 0.58 & 0.20 & 0.05 & 0.00 & 0.00 \\
\hline MFSBE & 0.29 & 0.37 & -0.12 & 0.01 & -0.18 & 0.08 & 0.14 & 0.01 & 0.00 & 0.03 \\
\hline MFSDE & 0.40 & 0.66 & -0.20 & -0.26 & 0.25 & 0.16 & 0.44 & 0.04 & 0.07 & 0.06 \\
\hline MFSFR & 0.47 & 0.55 & 0.07 & -0.09 & -0.31 & 0.22 & 0.31 & 0.00 & 0.01 & 0.10 \\
\hline MFSIE & 0.27 & 0.50 & 0.10 & 0.00 & 0.09 & 0.07 & 0.25 & 0.01 & 0.00 & 0.01 \\
\hline MFSIT & 0.46 & 0.56 & -0.23 & 0.18 & -0.25 & 0.21 & 0.31 & 0.05 & 0.03 & 0.06 \\
\hline MFSNL & 0.77 & 0.29 & -0.19 & 0.12 & 0.08 & 0.59 & 0.09 & 0.04 & 0.01 & 0.01 \\
\hline
\end{tabular}


Table 1. Balanced Panel (cont.)

\begin{tabular}{|c|c|c|c|c|c|c|c|c|c|c|}
\hline \multirow[t]{2}{*}{\begin{tabular}{|l|} 
Variable \\
\end{tabular}} & \multicolumn{5}{|c|}{ Loadings } & \multicolumn{5}{|c|}{ Loadings Squared } \\
\hline & F1 & F2 & F3 & F4 & F5 & F1 & F2 & F3 & F4 & F5 \\
\hline MTRAT & -0.10 & -0.19 & -0.16 & -0.18 & -0.19 & 0.01 & 0.04 & 0.03 & 0.03 & 0.04 \\
\hline MTRDE & -0.22 & -0.38 & -0.31 & -0.20 & -0.29 & 0.05 & 0.14 & 0.10 & 0.04 & 0.08 \\
\hline MTRES & -0.58 & -0.36 & -0.27 & -0.01 & 0.04 & 0.33 & 0.13 & 0.07 & 0.00 & 0.00 \\
\hline MTRFI & -0.05 & -0.12 & -0.02 & -0.18 & 0.24 & 0.00 & 0.01 & 0.00 & 0.03 & 0.06 \\
\hline MTRFR & -0.19 & -0.45 & -0.23 & -0.20 & -0.02 & 0.04 & 0.20 & 0.05 & 0.04 & 0.00 \\
\hline MTRIT & -0.12 & -0.41 & -0.27 & -0.27 & -0.32 & 0.01 & 0.17 & 0.07 & 0.07 & 0.10 \\
\hline MTRNL & -0.30 & -0.22 & -0.44 & -0.35 & -0.12 & 0.09 & 0.05 & 0.19 & 0.12 & 0.01 \\
\hline PCEAT & -0.01 & -0.11 & -0.15 & -0.06 & -0.21 & 0.00 & 0.01 & 0.02 & 0.00 & 0.04 \\
\hline PCEDE & -0.20 & -0.15 & -0.35 & 0.00 & -0.51 & 0.04 & 0.02 & 0.13 & 0.00 & 0.26 \\
\hline PCEES & -0.65 & -0.44 & -0.15 & 0.19 & 0.09 & 0.42 & 0.19 & 0.02 & 0.04 & 0.01 \\
\hline PCEFI & -0.06 & -0.15 & -0.49 & -0.12 & 0.38 & 0.00 & 0.02 & 0.24 & 0.01 & 0.14 \\
\hline PCEFR & -0.10 & -0.23 & -0.37 & 0.04 & -0.23 & 0.01 & 0.05 & 0.14 & 0.00 & 0.05 \\
\hline PCEIT & 0.01 & -0.64 & -0.26 & 0.08 & -0.14 & 0.00 & 0.41 & 0.07 & 0.01 & 0.02 \\
\hline PCENL & -0.36 & -0.05 & -0.21 & 0.02 & -0.27 & 0.13 & 0.00 & 0.04 & 0.00 & 0.07 \\
\hline PIHBE & -0.10 & -0.01 & -0.02 & 0.01 & 0.00 & 0.01 & 0.00 & 0.00 & 0.00 & 0.00 \\
\hline PIHFI & -0.01 & -0.03 & -0.04 & -0.05 & 0.13 & 0.00 & 0.00 & 0.00 & 0.00 & 0.02 \\
\hline PIHFR & -0.09 & -0.02 & -0.14 & -0.10 & -0.09 & 0.01 & 0.00 & 0.02 & 0.01 & 0.01 \\
\hline PIHNL & -0.06 & -0.07 & -0.14 & -0.21 & -0.13 & 0.00 & 0.01 & 0.02 & 0.05 & 0.02 \\
\hline RSLAT & -0.02 & -0.14 & -0.13 & -0.05 & -0.14 & 0.00 & 0.02 & 0.02 & 0.00 & 0.02 \\
\hline RSLBE & -0.20 & -0.23 & -0.17 & 0.09 & -0.10 & 0.04 & 0.05 & 0.03 & 0.01 & 0.01 \\
\hline RSLDE & -0.14 & -0.19 & -0.31 & 0.04 & -0.39 & 0.02 & 0.03 & 0.10 & 0.00 & 0.15 \\
\hline RSLFR & -0.08 & -0.12 & -0.11 & -0.01 & -0.07 & 0.01 & 0.01 & 0.01 & 0.00 & 0.00 \\
\hline RSLIE & -0.26 & -0.10 & -0.06 & -0.30 & -0.09 & 0.07 & 0.01 & 0.00 & 0.09 & 0.01 \\
\hline RSLNL & -0.34 & -0.04 & -0.05 & -0.02 & 0.02 & 0.12 & 0.00 & 0.00 & 0.00 & 0.00 \\
\hline STIAT & 0.05 & -0.69 & 0.35 & 0.05 & -0.04 & 0.00 & 0.48 & 0.12 & 0.00 & 0.00 \\
\hline STIBE & 0.22 & -0.58 & 0.17 & -0.03 & -0.16 & 0.05 & 0.34 & 0.03 & 0.00 & 0.02 \\
\hline STIDE & 0.12 & -0.64 & 0.22 & -0.13 & -0.16 & 0.01 & 0.41 & 0.05 & 0.02 & 0.03 \\
\hline STIES & 0.05 & -0.09 & -0.11 & 0.07 & -0.08 & 0.00 & 0.01 & 0.01 & 0.00 & 0.01 \\
\hline STIFI & 0.10 & -0.51 & 0.12 & 0.22 & 0.12 & 0.01 & 0.26 & 0.01 & 0.05 & 0.01 \\
\hline STIFR & 0.19 & -0.45 & 0.23 & -0.11 & 0.06 & 0.04 & 0.20 & 0.05 & 0.01 & 0.00 \\
\hline STIIIE & 0.11 & -0.22 & 0.15 & 0.06 & -0.05 & 0.01 & 0.05 & 0.02 & 0.00 & 0.00 \\
\hline STIIT & 0.22 & -0.45 & 0.21 & -0.01 & 0.00 & 0.05 & 0.20 & 0.05 & 0.00 & 0.00 \\
\hline STINL & 0.06 & -0.43 & -0.01 & -0.13 & -0.29 & 0.00 & 0.19 & 0.00 & 0.02 & 0.09 \\
\hline STIPT & 0.33 & -0.23 & -0.14 & 0.14 & -0.04 & 0.11 & 0.05 & 0.02 & 0.02 & 0.00 \\
\hline UNRAT & 0.23 & 0.44 & 0.00 & 0.34 & 0.06 & 0.05 & 0.19 & 0.00 & 0.12 & 0.00 \\
\hline UNRBE & 0.44 & 0.43 & 0.21 & -0.09 & -0.07 & 0.19 & 0.18 & 0.04 & 0.01 & 0.01 \\
\hline UNRDE & 0.47 & 0.52 & -0.04 & -0.12 & 0.43 & 0.22 & 0.27 & 0.00 & 0.01 & 0.18 \\
\hline UNRES & 0.74 & 0.37 & 0.21 & -0.13 & -0.27 & 0.55 & 0.13 & 0.05 & 0.02 & 0.07 \\
\hline UNRFR & 0.48 & 0.40 & 0.14 & -0.26 & -0.32 & 0.23 & 0.16 & 0.02 & 0.07 & 0.11 \\
\hline UNRFI & 0.09 & 0.52 & 0.41 & 0.11 & -0.39 & 0.01 & 0.28 & 0.17 & 0.01 & 0.16 \\
\hline UNRIE & 0.66 & 0.31 & 0.09 & 0.13 & -0.18 & 0.43 & 0.10 & 0.01 & 0.02 & 0.03 \\
\hline UNRIT & 0.19 & 0.31 & -0.09 & -0.24 & -0.05 & 0.04 & 0.10 & 0.01 & 0.06 & 0.00 \\
\hline UNRNL & 0.59 & 0.39 & -0.11 & -0.01 & 0.22 & 0.35 & 0.16 & 0.01 & 0.00 & 0.05 \\
\hline UNRPT & 0.35 & 0.51 & 0.09 & -0.31 & -0.20 & 0.12 & 0.26 & 0.01 & 0.10 & 0.04 \\
\hline WINAT & 0.05 & -0.02 & 0.04 & 0.16 & -0.09 & 0.00 & 0.00 & 0.00 & 0.03 & 0.01 \\
\hline WINDE & 0.17 & -0.32 & 0.05 & 0.10 & -0.47 & 0.03 & 0.10 & 0.00 & 0.01 & 0.22 \\
\hline WINFR & 0.76 & -0.32 & -0.26 & 0.30 & -0.01 & 0.58 & 0.11 & 0.07 & 0.09 & 0.00 \\
\hline WINIT & 0.74 & -0.35 & -0.14 & 0.18 & 0.02 & 0.55 & 0.12 & 0.02 & 0.03 & 0.00 \\
\hline XTRAT & -0.02 & -0.18 & -0.28 & -0.30 & -0.09 & 0.00 & 0.03 & 0.08 & 0.09 & 0.01 \\
\hline XTRDE & 0.02 & -0.40 & -0.15 & -0.38 & -0.21 & 0.00 & 0.16 & 0.02 & 0.15 & 0.04 \\
\hline XTRES & 0.00 & 0.23 & -0.12 & -0.52 & -0.02 & 0.00 & 0.05 & 0.01 & 0.27 & 0.00 \\
\hline XTRFI & -0.01 & 0.01 & -0.01 & -0.33 & 0.04 & 0.00 & 0.00 & 0.00 & 0.11 & 0.00 \\
\hline XTRFR & -0.04 & -0.33 & -0.10 & -0.53 & 0.04 & 0.00 & 0.11 & 0.01 & 0.29 & 0.00 \\
\hline XTRIT & 0.03 & -0.02 & -0.09 & -0.37 & -0.17 & 0.00 & 0.00 & 0.01 & 0.13 & 0.03 \\
\hline XTRNL & -0.14 & -0.17 & -0.42 & -0.42 & -0.27 & 0.02 & 0.03 & 0.18 & 0.18 & 0.07 \\
\hline
\end{tabular}


Table 2. Unbalanced Panel

\begin{tabular}{|c|c|c|c|c|c|c|}
\hline \multirow[t]{2}{*}{ Variable } & \multicolumn{3}{|c|}{ Loadings } & \multicolumn{3}{|c|}{ Loadings Squared } \\
\hline & F1 & $\mathrm{F} 2$ & F3 & $\mathrm{F} 1$ & $\mathrm{~F} 2$ & F3 \\
\hline MTDIE & 0.71 & -0.25 & -0.29 & 0.51 & 0.06 & 0.08 \\
\hline MTDNL & 0.47 & -0.33 & -0.26 & 0.22 & 0.11 & 0.07 \\
\hline MTDBE & 0.02 & -0.27 & -0.54 & 0.00 & 0.07 & 0.29 \\
\hline MTDPT & 0.23 & -0.30 & -0.36 & 0.05 & 0.09 & 0.13 \\
\hline PCDIE & 0.89 & 0.01 & 0.00 & 0.79 & 0.00 & 0.00 \\
\hline PCDBE & 0.37 & -0.13 & -0.13 & 0.14 & 0.02 & 0.02 \\
\hline PCDPT & 0.47 & -0.32 & 0.45 & 0.22 & 0.10 & 0.20 \\
\hline PCDNL & 0.57 & -0.06 & 0.05 & 0.33 & 0.00 & 0.00 \\
\hline PPIBE & 0.68 & -0.29 & -0.33 & 0.46 & 0.08 & 0.11 \\
\hline PPIPT & 0.40 & 0.00 & -0.18 & 0.16 & 0.00 & 0.03 \\
\hline PPIIT & 0.87 & -0.23 & -0.16 & 0.75 & 0.05 & 0.03 \\
\hline PPIIE & 0.26 & -0.24 & -0.23 & 0.07 & 0.06 & 0.05 \\
\hline ULCBE & 0.40 & 0.25 & 0.44 & 0.16 & 0.06 & 0.19 \\
\hline ULCDE & 0.25 & 0.01 & 0.39 & 0.06 & 0.00 & 0.15 \\
\hline ULCES & 0.57 & -0.08 & 0.27 & 0.32 & 0.01 & 0.07 \\
\hline ULCFI & -0.13 & -0.32 & 0.19 & 0.02 & 0.10 & 0.04 \\
\hline ULCFR & 0.18 & 0.07 & 0.51 & 0.03 & 0.00 & 0.26 \\
\hline ULCIT & 0.78 & -0.13 & 0.21 & 0.61 & 0.02 & 0.05 \\
\hline ULCNL & 0.04 & 0.18 & 0.33 & 0.00 & 0.03 & 0.11 \\
\hline WPIDE & 0.16 & -0.18 & -0.61 & 0.03 & 0.03 & 0.37 \\
\hline WPIFI & 0.48 & 0.22 & -0.19 & 0.23 & 0.05 & 0.04 \\
\hline WPIIT & 0.16 & -0.22 & 0.01 & 0.03 & 0.05 & 0.00 \\
\hline XTDNL & 0.45 & -0.33 & -0.35 & 0.20 & 0.11 & 0.12 \\
\hline XTDIE & 0.73 & -0.01 & -0.36 & 0.53 & 0.00 & 0.13 \\
\hline XTDBE & 0.00 & -0.26 & -0.48 & 0.00 & 0.07 & 0.23 \\
\hline XTDPT & 0.21 & -0.31 & -0.15 & 0.04 & 0.09 & 0.02 \\
\hline YEDIE & 0.91 & -0.18 & 0.05 & 0.82 & 0.03 & 0.00 \\
\hline YEDNL & 0.39 & -0.06 & 0.01 & 0.15 & 0.00 & 0.00 \\
\hline YEDBE & 0.50 & -0.09 & 0.12 & 0.25 & 0.01 & 0.01 \\
\hline YEDPT & 0.39 & -0.26 & 0.52 & 0.15 & 0.07 & 0.27 \\
\hline CAPIE & -0.78 & -0.12 & 0.02 & 0.62 & 0.01 & 0.00 \\
\hline CRDBE & -0.08 & -0.48 & 0.13 & 0.01 & 0.23 & 0.02 \\
\hline CRDDE & 0.12 & -0.18 & 0.27 & 0.02 & 0.03 & 0.07 \\
\hline CRDFR & 0.16 & -0.16 & 0.15 & 0.02 & 0.03 & 0.02 \\
\hline EEFAT & -0.03 & -0.03 & 0.42 & 0.00 & 0.00 & 0.18 \\
\hline EEFBE & -0.04 & -0.08 & 0.44 & 0.00 & 0.01 & 0.19 \\
\hline EEFDE & -0.06 & -0.03 & 0.43 & 0.00 & 0.00 & 0.19 \\
\hline EEFES & -0.17 & -0.53 & 0.20 & 0.03 & 0.28 & 0.04 \\
\hline EEFFI & -0.25 & -0.45 & -0.16 & 0.06 & 0.20 & 0.03 \\
\hline EEFFR & 0.00 & -0.03 & 0.41 & 0.00 & 0.00 & 0.17 \\
\hline EEFIE & -0.06 & -0.11 & 0.37 & 0.00 & 0.01 & 0.14 \\
\hline EEFIT & -0.30 & -0.18 & 0.15 & 0.09 & 0.03 & 0.02 \\
\hline EEFNL & -0.08 & 0.02 & 0.45 & 0.01 & 0.00 & 0.20 \\
\hline EEFPT & -0.28 & -0.18 & 0.07 & 0.08 & 0.03 & 0.01 \\
\hline ERNBE & 0.68 & -0.13 & 0.21 & 0.46 & 0.02 & 0.05 \\
\hline ERNIE & 0.68 & -0.15 & 0.10 & 0.46 & 0.02 & 0.01 \\
\hline GDPBE & -0.15 & -0.43 & -0.27 & 0.02 & 0.19 & 0.07 \\
\hline GDPIE & -0.30 & -0.21 & -0.21 & 0.09 & 0.04 & 0.04 \\
\hline GDPPT & -0.18 & -0.32 & -0.13 & 0.03 & 0.10 & 0.02 \\
\hline HSTDE & 0.10 & 0.12 & -0.28 & 0.01 & 0.01 & 0.08 \\
\hline LFNAT & 0.20 & 0.08 & 0.01 & 0.04 & 0.01 & 0.00 \\
\hline LFNBE & 0.17 & -0.02 & -0.11 & 0.03 & 0.00 & 0.01 \\
\hline LFNDE & 0.21 & 0.04 & -0.21 & 0.05 & 0.00 & 0.05 \\
\hline LFNIE & -0.24 & 0.22 & -0.03 & 0.06 & 0.05 & 0.00 \\
\hline LFNPT & -0.04 & -0.17 & 0.00 & 0.00 & 0.03 & 0.00 \\
\hline LNIBE & -0.27 & -0.33 & 0.26 & 0.07 & 0.11 & 0.07 \\
\hline LNIDE & 0.32 & -0.20 & 0.24 & 0.10 & 0.04 & 0.06 \\
\hline LNIIT & 0.00 & -0.38 & 0.53 & 0.00 & 0.14 & 0.28 \\
\hline LNNNL & -0.41 & -0.45 & 0.28 & 0.17 & 0.20 & 0.08 \\
\hline LTIES & 0.14 & -0.36 & 0.01 & 0.02 & 0.13 & 0.00 \\
\hline LTIPT & -0.03 & -0.34 & -0.28 & 0.00 & 0.12 & 0.08 \\
\hline
\end{tabular}


Table 2. Unbalanced Panel (cont.)

\begin{tabular}{|c|c|c|c|c|c|c|}
\hline \multirow[t]{2}{*}{ Variable } & \multicolumn{3}{|c|}{ Loadings } & \multicolumn{3}{|c|}{ Loadings Squared } \\
\hline & $\mathrm{F} 1$ & $\mathrm{~F} 2$ & F3 & $\mathrm{F} 1$ & $\mathrm{~F} 2$ & F3 \\
\hline M1AT & -0.41 & 0.20 & -0.24 & 0.16 & 0.04 & 0.06 \\
\hline M1BE & -0.09 & 0.15 & 0.05 & 0.01 & 0.02 & 0.00 \\
\hline M1DE & -0.23 & 0.14 & 0.21 & 0.06 & 0.02 & 0.04 \\
\hline M1ES & -0.04 & -0.48 & 0.22 & 0.00 & 0.23 & 0.05 \\
\hline M1FI & 0.16 & -0.03 & -0.16 & 0.03 & 0.00 & 0.03 \\
\hline M1FR & 0.23 & -0.15 & 0.05 & 0.05 & 0.02 & 0.00 \\
\hline M1IE & -0.21 & -0.06 & -0.28 & 0.05 & 0.00 & 0.08 \\
\hline M1IT & 0.23 & -0.04 & 0.10 & 0.05 & 0.00 & 0.01 \\
\hline M1NL & -0.22 & 0.19 & 0.11 & 0.05 & 0.04 & 0.01 \\
\hline M1PT & 0.05 & 0.01 & 0.26 & 0.00 & 0.00 & 0.07 \\
\hline M2AT & 0.35 & 0.21 & 0.26 & 0.12 & 0.04 & 0.07 \\
\hline M2BE & -0.13 & -0.01 & 0.01 & 0.02 & 0.00 & 0.00 \\
\hline M2DE & 0.02 & 0.38 & 0.25 & 0.00 & 0.14 & 0.06 \\
\hline M2ES & 0.59 & -0.28 & 0.12 & 0.35 & 0.08 & 0.01 \\
\hline $\mathrm{M} 2 \mathrm{FI}$ & 0.41 & -0.37 & 0.13 & 0.16 & 0.14 & 0.02 \\
\hline M2FR & 0.40 & -0.31 & -0.11 & 0.16 & 0.10 & 0.01 \\
\hline M2IE & -0.02 & 0.11 & -0.11 & 0.00 & 0.01 & 0.01 \\
\hline M2IT & 0.53 & 0.09 & 0.22 & 0.28 & 0.01 & 0.05 \\
\hline M2NL & 0.10 & -0.07 & 0.36 & 0.01 & 0.00 & 0.13 \\
\hline M2PT & 0.70 & -0.01 & 0.27 & 0.48 & 0.00 & 0.07 \\
\hline M3AT & 0.36 & 0.20 & 0.24 & 0.13 & 0.04 & 0.06 \\
\hline M3BE & -0.05 & 0.16 & 0.12 & 0.00 & 0.03 & 0.01 \\
\hline M3DE & 0.22 & 0.30 & 0.12 & 0.05 & 0.09 & 0.02 \\
\hline M3ES & 0.52 & -0.33 & 0.14 & 0.27 & 0.11 & 0.02 \\
\hline M3FI & 0.31 & -0.24 & 0.13 & 0.10 & 0.06 & 0.02 \\
\hline M3FR & 0.35 & -0.50 & 0.25 & 0.12 & 0.25 & 0.06 \\
\hline M3IE & -0.08 & 0.08 & -0.21 & 0.01 & 0.01 & 0.04 \\
\hline M3IT & 0.52 & 0.04 & 0.24 & 0.27 & 0.00 & 0.06 \\
\hline M3NL & 0.08 & -0.10 & 0.36 & 0.01 & 0.01 & 0.13 \\
\hline M3PT & 0.69 & -0.05 & 0.25 & 0.47 & 0.00 & 0.06 \\
\hline MFBAT & -0.10 & -0.78 & 0.37 & 0.01 & 0.61 & 0.14 \\
\hline MFBES & -0.70 & -0.68 & -0.09 & 0.49 & 0.46 & 0.01 \\
\hline MFBFI & -0.39 & -0.61 & -0.38 & 0.15 & 0.37 & 0.14 \\
\hline MFBPT & -0.57 & -0.72 & 0.07 & 0.33 & 0.52 & 0.00 \\
\hline MFOBE & -0.33 & -0.59 & -0.14 & 0.11 & 0.35 & 0.02 \\
\hline MFODE & -0.38 & -0.67 & -0.06 & 0.15 & 0.44 & 0.00 \\
\hline MFOES & -0.43 & -0.56 & -0.08 & 0.18 & 0.32 & 0.01 \\
\hline MFOFI & -0.28 & -0.11 & -0.55 & 0.08 & 0.01 & 0.30 \\
\hline MFOFR & -0.41 & -0.71 & 0.17 & 0.17 & 0.51 & 0.03 \\
\hline MFOIE & -0.65 & -0.28 & -0.19 & 0.42 & 0.08 & 0.04 \\
\hline MFOIT & -0.63 & -0.59 & -0.02 & 0.39 & 0.34 & 0.00 \\
\hline MFONL & -0.55 & -0.38 & -0.20 & 0.31 & 0.15 & 0.04 \\
\hline MFOPT & -0.50 & -0.69 & 0.00 & 0.25 & 0.48 & 0.00 \\
\hline MFSAT & 0.14 & 0.83 & -0.21 & 0.02 & 0.69 & 0.04 \\
\hline MFSES & 0.65 & 0.70 & 0.19 & 0.42 & 0.49 & 0.04 \\
\hline MFSPT & 0.45 & 0.48 & 0.17 & 0.21 & 0.23 & 0.03 \\
\hline MTRBE & -0.07 & -0.26 & -0.14 & 0.00 & 0.07 & 0.02 \\
\hline MTRIE & -0.47 & -0.07 & -0.44 & 0.22 & 0.00 & 0.19 \\
\hline MTRPT & -0.25 & -0.29 & -0.02 & 0.06 & 0.08 & 0.00 \\
\hline PCEBE & -0.19 & -0.38 & 0.06 & 0.04 & 0.15 & 0.00 \\
\hline PCEIE & -0.48 & -0.05 & -0.19 & 0.23 & 0.00 & 0.04 \\
\hline PCEPT & -0.26 & -0.29 & 0.09 & 0.07 & 0.08 & 0.01 \\
\hline PIHDE & -0.03 & -0.06 & -0.10 & 0.00 & 0.00 & 0.01 \\
\hline PIHPT & -0.01 & 0.06 & -0.01 & 0.00 & 0.00 & 0.00 \\
\hline RSLFI & -0.30 & -0.20 & -0.20 & 0.09 & 0.04 & 0.04 \\
\hline RSLIT & 0.01 & -0.04 & 0.04 & 0.00 & 0.00 & 0.00 \\
\hline RSLPT & 0.01 & -0.17 & 0.23 & 0.00 & 0.03 & 0.05 \\
\hline WINBE & 0.12 & -0.32 & 0.24 & 0.01 & 0.10 & 0.06 \\
\hline WINFI & 0.26 & -0.44 & -0.06 & 0.07 & 0.19 & 0.00 \\
\hline WINNL & -0.06 & -0.16 & 0.16 & 0.00 & 0.02 & 0.03 \\
\hline XTRBE & -0.06 & -0.21 & -0.19 & 0.00 & 0.04 & 0.04 \\
\hline XTRIE & -0.41 & -0.08 & -0.46 & 0.17 & 0.01 & 0.21 \\
\hline XTRPT & -0.17 & -0.35 & -0.31 & 0.03 & 0.12 & 0.09 \\
\hline
\end{tabular}


Coding for the variables consists in three characters for the concept portrayed by the variable and two characters for the country. Thus, variable CPIAT stands for concept CPI (Consumer Price Index) for country Austria (AT). The acronyms used in the table are explained below. (One important point to keep in mind is the sometimes differing concepts across countries, since this forces a rather loose labelling for the variables.)

\section{Countries}

\begin{tabular}{|l|l|}
\hline AT & Austria \\
\hline BE & Belgium \\
\hline DE & Germany \\
\hline ES & Spain \\
\hline FI & Finland \\
\hline FR & France \\
\hline IE & Ireland \\
\hline IT & Italy \\
\hline NL & Netherlands \\
\hline PT & Portugal \\
\hline
\end{tabular}




\section{Concepts}

\begin{tabular}{|l|l|}
\hline \multicolumn{2}{|l|}{ Balanced Panel Variables } \\
\hline CPI & Consumer Price Index \\
\hline MTD & Import Deflator \\
\hline PCD & Private Consumption Deflator \\
\hline PPI & Producer's Price Index \\
\hline XTD & Export Deflator \\
\hline YED & GDP Deflator \\
\hline CAP & Capacity Utilisation \\
\hline ERN & Total Earnings \\
\hline HST & Housing Starts \\
\hline LFN & Labour Force \\
\hline LNN & Total Employment \\
\hline LTI & Long-term Interest Rate \\
\hline MFB & Manufacturing book-orders \\
\hline MFS & Level of Stocks in Manufacturing \\
\hline MTR & Total Imports \\
\hline PCE & Private Consumer Expenditure \\
\hline PIH & Housing Permits \\
\hline RSL & Retail Sales \\
\hline STI & Short-Term Interest Rate \\
\hline UNR & Unemployment Rate \\
\hline WIN & Total Compensation of Employees \\
\hline XTR & Total Imports \\
\hline Unbalanced Panel Variables \\
\hline ULC & Unit Labour Costs \\
\hline M1 & M1 \\
\hline M2 & M2 \\
\hline M3 & M3 \\
\hline MFO & New Orders in Manufacturing \\
\hline
\end{tabular}




\section{Appendix B. A Discussion on the Forecasting Framework}

As said in the main text, forecast regressions are based on (B.1), which is expression (3.1) repeated here for convenience. As before, $y_{t}$ is the variable of interest, assumed to be $\mathrm{I}(1), z_{t}$ is the indicator variable under test, assumed to be $\mathrm{I}(0)$, and $\varepsilon_{t}$ is a well-behaved error term, while $h$ stands for the number of periods ahead for which the forecast has to be performed. An explicit model for $z_{t}$ may be summarised by (B.2), in which a (stochastic) relationship is assumed to exist between that variable and variable $x_{t}$. The latter is a vector variable that may comprise lags of $z_{t}$ and lagged values of $\Delta y_{t}$, but which in general will be considered to contain supplementary information. ${ }^{13}$ Obviously, variable $z_{t}$ is assumed to be impossible to forecast with perfect accuracy.

$$
\begin{aligned}
& \frac{y_{t+h}-y_{t}}{h}=A(L) \cdot \Delta y_{t}+B(L) \cdot z_{t}+\varepsilon_{t} \\
& z_{t}=\Phi\left(x_{t}\right)
\end{aligned}
$$

As already expressed in the main text, expression (B.1) is non-recursive in that all information needed to derive an $h$-step-ahead forecast is available at time $t$. Instead, the normal forecasting practice starts from a recursive system like (B.3), a repetition of (3.2) in the main text. A professional forecaster would thus draw a forecast by recursing on (B.3) and (B.2), and would probably be willing to spend some effort in fine-tuning his/her view of the future evolution of $z_{t}$, based on the assessment made for $x_{t}$.

$$
\Delta y_{t+1}=A(L) \cdot \Delta y_{t}+B(L) \cdot z_{t}+\varepsilon_{t}
$$

Expressions (B.4) and (B.5) express how $h$-step-ahead forecasts are obtained with the two approaches. One notable difference between the two expressions is the presence of expectations on the right-hand side of the recursive system, and its absence in the nonrecursive one (hence their name).

$$
\begin{aligned}
& E_{t} \frac{y_{t+h}-y_{t}}{h}=A(L) \cdot \Delta y_{t}+B(L) \cdot z_{t} \\
& E_{t} \Delta y_{t+h}=A(L) \cdot E_{t} \Delta y_{t+h-1}+B(L) \cdot E_{t} z_{t+h-1}
\end{aligned}
$$

One problem with (B.4) is that it does not clearly define what is the data-generating process for $z_{t}$, and thus skips entirely the information that could be gained with (B.2). Obviously, if $z_{t}$ only depends on its own lags and lagged values of $y_{t}$ there is a one-to-one

13 It could also comprise contemporaneous values of $\Delta y_{t}$ without affecting results, although this would compromise the use of $z_{t}$ in forecasting. 
mapping between (B.4) and (B.5), but if the variable is explained by other variables then necessarily (B.4) lacks information. This can be seen intuitively by noting that $E_{t} z_{t+h-1}$ only depends, in the latter case, on contemporaneous and lagged values of $z_{t}$ and $\Delta y_{t}$, all of which already enter (B.4). However, if (B.2) contains extraneous information, the forecasting equation (B.4) will miss relevant regressors. Further to that, it is widely believed that observations $h$ periods apart are less related than contiguous observations, and this may reduce the significance of the estimated parameters in (B.4), and increase the volatility of the forecast. On the other hand, it has to be admitted that the single-step forecast of (B.4) minimises the effect of errors in the model specification, as these are not propagated to periods in between, as is the case in (B.5). It is very difficult to assess formally the relative importance of all these factors, as they involve testing the out-ofsample robustness of the models, a task for which standard in-sample tests may fail to give a proper answer.

All in all, it is difficult to decide a priori whether (B.1) or (B.3) is preferable as a forecasting device. This paper has opted for (B.1) not just because it is now widely accepted, but rather because we don't feel comfortable specifying a generating model for the indicators on which we will focus: dynamic factors extracted from a rich dataset. ${ }^{14}$ For us, expression (B.1) presents the convenient advantage of not requiring this information. Nonetheless, a number of tests were performed to ensure that the forecasting ability of (B.1) in normal circumstances matches that of (B.3). Thus, loosely speaking, our null hypothesis is that (B.1) is not worse in forecasting than (B.3). Unfortunately, the test cannot be treated explicitly as a standard one, because our centre of interest is the robustness of each system in the face of unforeseen structural breaks, and on this econometrics has not yet much to tell, see e.g. Clements and Hendry (1998). The test loosely proposed is thus explicitly one of out-of-sample robustness in the sample under analysis. In this respect, a relatively large number of tests were run in which either (B.1) or (B.3) were slightly changed, as local alternatives to the original system, and forecasting tests were run. The relevance of this step lies in the fact that a consistently worse performance of (B.1) would make the forecasting tests included in the rest of the paper almost irrelevant.

A number of out-of-sample exercises were run with inflation measured by the HICP and, where required, GDP as an indicator. GDP was chosen as an indicator for the bivariate system below because the inflation-output system is fairly standard in the literature and known to work relatively well: as a benchmark, correspondingly, it may bias results against the non-recursive system, which is the system under test. In all the systems, the equation for GDP played the role of (B.2). Both variables were in logs, the GDP also in

\footnotetext{
${ }^{14}$ In other words, factors are meant to be able to replace all variables that could appear in (B.1) with no significant loss of information. Under this assumption, (B.2) contains no relevant forecasting information and can thus be ignored.
} 
first difference. In each test, the system was changed to homogenise the variables forecast by the two equations, in ways described below.

\section{Test 1. Standard recursive system against re-expressed non-recursive system}

In the first test (B.4) was changed into (B.4') and tested against (B.5). When GDP was used as an indicator, the recursive system was a VAR with inflation and output. In this guise, both the recursive and the non-recursive system modelled the first difference of HICP.

$$
E_{t} \Delta y_{t+h}=A(L) \cdot \Delta y_{t}+B(L) \cdot z_{t}
$$

\section{Test 2. Re-expressed recursive system against standard non-recursive system}

The second test changed the definition of (B.5), in order for it to model the same variable as (B.4), as in (B.5'). Expression (B.5') is nothing but a standard one-step-ahead recursive equation modelling the same variable as (B.1).

$$
E_{t} \frac{y_{t+h}-y_{t}}{h}=A(L) \cdot E_{t} \frac{y_{t+h-1}-y_{t-1}}{h}+B(L) \cdot E_{t} z_{t+h-1}
$$

\section{Test 3. Cumulated recursive forecasts against standard non-recursive forecasts}

The third test took (B.4) and (B.5) unchanged, but cumulated the $h$ recursive forecasts of (B.5) in order to match the variable generated by (B.4).

\section{Test 4. Differenced non-recursive forecasts against standard recursive forecasts}

Finally, the fourth test also used (B.4) and (B.5) unchanged, but took first differences of the forecasts generated by the non-recursive system to match the variable generated by (B.5). ${ }^{15}$

Table 1 collects the relative size of the root mean square error (henceforth RMSE) of the 1-step-ahead to 4-step-ahead forecasts of the chosen non-recursive system compared with the more standard recursive one, for both the univariate (i.e., inflation only) system and the bivariate one (i.e., inflation and output). ${ }^{16}$ A number lower than one in a particular cell means that the recursive system is to be preferred, and the converse in the other case. ${ }^{17}$ Standard errors for the ratios, reported between parentheses, are a delta-method first-order approximation to the variance of the ratio, corrected for heteroskedasticity and autocorrelation using the Newey-West non-parametric method. Although the evidence on the relative merits of both equations is mixed, results shown give ground to our claim that (B.4) is an appropriate tool for the exercise at hand.

\footnotetext{
${ }^{15}$ More precisely, calling $\Delta_{h} y_{t+h} \exists y_{t+h^{-}} y_{t}$, the forecast is $E_{t} \Delta_{h} y_{t+h^{-}} E_{t} \Delta_{h-1} y_{t+h-1}$.

${ }^{16}$ The forecasting equations used in Table 1 included 4 lags of inflation and, where applicable, output. The out-of-sample tests performed are described in the main text.

${ }^{17}$ By construction, the ratio for the 1-step-ahead forecasts is one.
} 
Table 1. Recursive and non-Recursive Systems

Relative Performance

\begin{tabular}{|c|c|c|c|c|}
\hline & \multicolumn{4}{|c|}{ Steps Ahead } \\
\hline & 1 & 2 & 3 & 4 \\
\hline \multicolumn{5}{|c|}{ Test 1: standard recursive forecast against non-standard non-recursive forecast } \\
\hline Univariate & $1.00(0.00)$ & $0.98 \quad(0.20)$ & $0.95 \quad(0.41)$ & $0.90(0.52)$ \\
\hline Bivariate & $1.00(0.00)$ & $0.99(0.11)$ & $0.97(0.28)$ & $0.99(0.29)$ \\
\hline \multicolumn{5}{|c|}{ Test 2: non-standard recursive forecast against standard non-recursive forecast } \\
\hline Univariate & $1.00(0.00)$ & $1.00(0.09)$ & $1.05(0.26)$ & $1.06(0.17)$ \\
\hline Bivariate & $1.00(0.00)$ & $1.01(0.08)$ & $1.12(0.38)$ & $1.15(0.19)$ \\
\hline \multicolumn{5}{|c|}{ Test 3: cumulation of recursive forecasts against non-recursive forecast } \\
\hline Univariate & $1.00(0.00)$ & $0.98(0.20)$ & $0.92(0.41)$ & $0.87(0.55)$ \\
\hline Bivariate & $1.00(0.00)$ & $1.01(0.11)$ & $0.99(0.30)$ & $1.00 \quad(0.32)$ \\
\hline \multicolumn{5}{|c|}{ Test 4: recursive forecast against decumulated non-recursive forecasts } \\
\hline Univariate & $1.00(0.00)$ & $0.99(0.20)$ & $0.94(0.41)$ & $0.88(0.55)$ \\
\hline Bivariate & $1.00(0.00)$ & $1.00(0.11)$ & $0.96(0.30)$ & $0.98(0.32)$ \\
\hline
\end{tabular}

N.B.: A value lower than one indicates the recursive system is to be preferred 


\section{Appendix C. Description of Data}

A total of 35 series per country were considered for the creation of the dataset. The data set comprises real variables, national account deflators, and different prices, monetary and credit variables, interest rates, labour statistics and inventories of finished and ordered manufacturing goods. Only $68 \%$ of the total data are available for the 10 countries analysed over the sample period (see attached Table). Going beyond this overall picture the following points can be made:

1. The countries for which severe problems arise in terms of availability are Germany, Ireland, Austria and Portugal, countries for which almost half of the series are not available. For Germany the problem arises from the lack for "Germany as a whole" prior to 1991 for most series (total share of available data is $43 \%$ only). Data for Ireland is mostly annual, while for Austria and Portugal starting dates for many series are only as of 1985 and 1998. Also worth mentioning is Belgium for which some series start only in 1985.

2. Some series are not available for all countries, for example wholesale sales data is available only for France and Finland. Housing starts data, which covers 18\%, is available for Belgium, Germany, Spain, France, Netherlands, Austria and Finland. Credit to non-financial institutions and to individuals data $(21.9 \%$ and $25.4 \%$ covering sample respectively) are available only for Belgium, Germany, and France and for a very short time span as well. WPI (33.8\%) is available only for Germany, Ireland, Italy, Austria and Finland. Unit labour costs are covered by only $40 \%$ (no data is available for Ireland Austria, Portugal and German data starts in 1991q1).

3. Other series are available only with annual frequencies for many countries, as labour force and for others namely long-term interest rates have late starting dates (after1986) for all countries except Belgium and Spain (after 1978). 


\begin{tabular}{|c|c|c|c|c|c|c|c|c|c|}
\hline \multirow{2}{*}{ Series } & \multicolumn{9}{|c|}{ Countries } \\
\hline & \multicolumn{3}{|c|}{ Belgium } & \multicolumn{3}{|c|}{ Germany } & \multicolumn{3}{|c|}{ Spain } \\
\hline & Availability & Observations & Coverage(a) & Availability & Observations & Coverage(a) & Availability & Observations & Coverage(a) \\
\hline Ind'I Production Total (OECD, MEI) & 70q1-99q1 & 117 & $99 \%$ & $70 q 1-99 q 1$ & 117 & $\mathbf{9 9 \%}$ & 70q1-99q1 & 117 & $99 \%$ \\
\hline Capacity Utilization (EC Surveys and OECD, MEI*) & $73 q 1-99 q 2$ & 106 & $90 \%$ & $80 q 1-99 q 2$ & 78 & $66 \%$ & $70 q 1-99 q 2^{*}$ & 118 & $100 \%$ \\
\hline GDP (OECD, QNA and BIS*) & $85 q 1-99 q 2$ & 61 & $52 \%$ & $91 \mathrm{q1}-99 \mathrm{q} 1(\mathrm{~b})$ & 34 & $29 \%$ & $70 q 1-99 q 2$ & 118 & $100 \%$ \\
\hline Labour Force (OECD, Labour Stats. and BIS*) & $70 q 1-98 q 4$ & 29 & $25 \%$ & $70 q 1-98 q 4$ & 29 & $25 \%$ & $70 q 1-99 q 2^{*}$ & 118 & $100 \%$ \\
\hline Employment (OECD, Labour Stats. and BIS*) & $85 q 1-99 q 1^{*}$ & 57 & $48 \%$ & $91 q 1-99 q 1(b)^{*}$ & 33 & $28 \%$ & $70 q 1-99 q 1^{*}$ & 117 & $\mathbf{9 9 \%}$ \\
\hline |Unemployment Rate (BIS) & $70 q 1-99 q 2$ & 118 & $100 \%$ & $92 q 1-99 q 2(b)$ & 30 & $25 \%$ & $70 q 1-99 q 2$ & 118 & $100 \%$ \\
\hline |Retail Sales (OECD, MEI) & $76 q 1-99 q 2$ & 94 & $80 \%$ & $70 q 1-99 q 2$ & 118 & $100 \%$ & $95 q 1-99 q 2$ & 18 & $15 \%$ \\
\hline Wholesale Sales (OECD, MEI) & & & $0 \%$ & & & $0 \%$ & & & $0 \%$ \\
\hline Personal Consumption Expenditure (OECD, QNA) & $85 q 1-99 q 2$ & 61 & $52 \%$ & $92 \mathrm{q} 1-99 \mathrm{q} 2(\mathrm{~b})$ & 34 & $29 \%$ & $70 q 1-99 q 2$ & 118 & $100 \%$ \\
\hline Housing Starts, Construction put in place (OECD, MEI) & 70q1-99q1 & 117 & $\mathbf{9 9 \%}$ & $91 q 1-99 q 1$ & 33 & $28 \%$ & $72 q 1-99 q 2$ & 110 & $93 \%$ \\
\hline Permits Issued (OECD, MEI) & $70 q 1-99 q 1$ & 117 & $\mathbf{9 9} \%$ & $79 q 1-99 q 2$ & 82 & $69 \%$ & $92 q 1-99 q 2$ & 30 & $25 \%$ \\
\hline Stocks of finished goods in manufacturing, Survey Assessme & 70q1-99q2 & 118 & $100 \%$ & 70q1-99q2 & 118 & $100 \%$ & $87 q 1-99 q 2$ & 50 & $42 \%$ \\
\hline Orders in manufacturing, Survey Assessment (EC Survey) & 70q1-99q2 & 118 & $100 \%$ & $70 q 1-99 q 2$ & 118 & $100 \%$ & $87 q 1-99 q 2$ & 50 & $42 \%$ \\
\hline Book Orders, Survey Assessment (EC Survey) & $70 q 1-99 q 2$ & 118 & $100 \%$ & $70 q 1-99 q 2$ & 118 & $100 \%$ & $87 q 1-99 q 2$ & 50 & $42 \%$ \\
\hline Effective Exchange Rate (ECB Database) & $83 q 4-99 q 2$ & 66 & $56 \%$ & $83 q 4-99 q 2$ & 66 & $56 \%$ & $83 q 4-99 q 2$ & 66 & $56 \%$ \\
\hline Short-Term Interest Rates (Derived ECB database, and AMECO & $91 q 1-99 q 2(c)$ & 34 & $29 \%$ & $70 q 2-99 q 2$ & 118 & $100 \%$ & $77 q 2-99 q 2$ & 118 & $100 \%$ \\
\hline Long-Term Interest Rates (Derived ECB database) & $78 q 1-99 q 2(c)$ & 86 & $73 \%$ & 91q1-99q2(c) & 34 & $29 \%$ & $78 q 3-99 q 2(c)$ & 86 & $73 \%$ \\
\hline Money Stock M2 (ECB database) & $80 q 2-99 q 2$ & 78 & $66 \%$ & $80 q 2-99 q 2$ & 78 & $66 \%$ & $80 q 2-99 q 2$ & 78 & $66 \%$ \\
\hline Money Stock M3 (ECB database) & $80 q 2-99 q 2$ & 78 & $66 \%$ & $80 q 2-99 q 2$ & 78 & $66 \%$ & $80 q 2-99 q 2$ & 78 & $66 \%$ \\
\hline Credit to non financial institutions (BIS) & $80 q 1-98 q 4$ & 76 & $64 \%$ & $70 q 1-97 q 3$ & 110 & $93 \%$ & & & $0 \%$ \\
\hline Credit to Individuals (BIS) & $80 q 1-98 q 4$ & 76 & $64 \%$ & $70 q 2-97 q 4$ & 111 & $94 \%$ & & & $0 \%$ \\
\hline PPI Finished goods (OECD, MEI, and ECB database ${ }^{*}$ ) & $80 q 1-99 q 2$ & 78 & $66 \%$ & $70 q 1-99 q 2$ & 118 & $100 \%$ & $70 q 1-99 q 2$ & 118 & $100 \%$ \\
\hline WPI (ECB database* and BIS**) & & & $0 \%$ & $91 q 1-99 q 2^{*}$ & 34 & $29 \%$ & & & $0 \%$ \\
\hline |CPI (OECD, MEI) & $70 q 1-99 q 2$ & 118 & $100 \%$ & $70 q 1-99 q 2$ & 118 & $100 \%$ & $70 q 1-99 q 2$ & 118 & $100 \%$ \\
\hline Private Cons.Deflator (OECD, QNA) & $85 q 1-99 q 2$ & 58 & $49 \%$ & $92 q 1-99 q 2(b)$ & 34 & $29 \%$ & $70 q 1-99 q 2$ & 118 & $100 \%$ \\
\hline GDP deflator (OECD, QNA) & $85 q 1-99 q 2$ & 58 & $49 \%$ & $92 q 1-99 q 2(b)$ & 34 & $29 \%$ & $70 q 1-99 q 2$ & 118 & $100 \%$ \\
\hline Government Consumption Deflator (OECD, QNA) & $85 q 1-99 q 2$ & 58 & $49 \%$ & $91 q 1-99 q 2$ & 34 & $29 \%$ & 70q1-99q2 & 118 & $100 \%$ \\
\hline Gross fixed capital formation Deflator (OECD, QNA) & $85 q 1-99 q 2$ & 58 & $49 \%$ & $91 q 1-99 q 2$ & 34 & $29 \%$ & $70 q 1-99 q 2$ & 118 & $100 \%$ \\
\hline Exports Deflator (OECD, QNA) & $85 q 1-99 q 2$ & 58 & $49 \%$ & $92 q 1-99 q 2(b)$ & 34 & $29 \%$ & $70 q 1-99 q 2$ & 118 & $100 \%$ \\
\hline Imports Deflator (OECD, QNA) & $85 q 1-99 q 2$ & 58 & $49 \%$ & $92 q 1-99 q 2(b)$ & 34 & $29 \%$ & $70 q 1-99 q 2$ & 118 & $100 \%$ \\
\hline Compensation of Employees (OECD,QNA) & $85 q 1-99 q 2$ & 58 & $49 \%$ & $92 q 1-99 q 2(b)$ & 34 & $29 \%$ & $95 q 1-99 q 2$ & 118 & $100 \%$ \\
\hline Hourly Earnings (OECD, MEI) & $80 q 1-99 q 2$ & 78 & $66 \%$ & $70 q 1-99 q 2$ & 118 & $100 \%$ & $70 q 1-99 q 2$ & 118 & $100 \%$ \\
\hline Real Exports (OECD, QNA) & $85 q 1-99 q 2$ & 58 & $49 \%$ & $92 q 1-99 q 2(b)$ & 34 & $29 \%$ & $70 q 1-99 q 2$ & 118 & $100 \%$ \\
\hline Real Imports (OECD, QNA) & $85 q 1-99 q 2$ & 58 & $49 \%$ & $92 q 1-99 q 2(b)$ & 34 & $29 \%$ & $70 q 1-99 q 2$ & 118 & $100 \%$ \\
\hline ULC (BIS) & $85 q 1-99 q 2$ & 58 & $49 \%$ & $92 q 1-99 q 2(b)$ & 34 & $29 \%$ & $70 q 1-99 q 2$ & 118 & $100 \%$ \\
\hline
\end{tabular}

(a) Coverage stands for the ratio between available data and total number of observations.

(b) Data for Germany is available in most cases only as of 1991, however it is possible to obtain longer series by rescaling and joining to Western Germany series.

(c) Some series have been rescalled and linked to other series as done to solve the German Unification issue and to have series that go as far as 1970.

e.g.This was done for Long - term and Short-term interest rates using AMECO annual data for past data. 


\begin{tabular}{|c|c|c|c|c|c|c|c|c|c|}
\hline \multirow{2}{*}{ Series } & \multicolumn{9}{|c|}{ Countries } \\
\hline & \multicolumn{3}{|c|}{ France } & \multicolumn{3}{|c|}{ Ireland } & \multicolumn{3}{|c|}{ Italy } \\
\hline & Availability & Observations & Coverage(a) & Availability & Observations & Coverage(a) & Availability & Observations & Coverage(a) \\
\hline Ind'I Production Total (OECD, MEI) & $70 q 1-99 q 1$ & 117 & $99 \%$ & $75 q 3-99 q 2$ & 98 & $83 \%$ & $70 q 1-99 q 1$ & 117 & $\mathbf{9 9 \%}$ \\
\hline Capacity Utilization (EC Surveys and OECD, MEI*) & $76 q 1-99 q 2$ & 94 & $80 \%$ & $76 q 1-99 q 2^{*}$ & 94 & $80 \%$ & $70 q 1-99 q 2$ & 118 & $100 \%$ \\
\hline GDP (OECD, QNA and BIS*) & $70 q 1-99 q 2$ & 118 & $100 \%$ & $75 q 1-97 q 4^{*}$ & 24 & $20 \%$ & $70 q 1-99 q 2$ & 118 & $100 \%$ \\
\hline Labour Force (OECD, Labour Stats. and BIS*) & $70 q 1-99 q 2^{*}$ & 118 & $100 \%$ & $70 q 1-97 q 4$ & 28 & $24 \%$ & $70 q 1-99 q 2^{*}$ & 118 & $100 \%$ \\
\hline Employment (OECD, Labour Stats. and BIS*) & $70 q 1-98 q 4$ & 29 & $25 \%$ & $70 q 1-97 q 4$ & 28 & $24 \%$ & $70 q 1-99 q 1^{*}$ & 119 & $101 \%$ \\
\hline Unemployment Rate (BIS) & $70 q 1-99 q 2$ & 118 & $100 \%$ & $70 q 1-99 q 2$ & 118 & $100 \%$ & $70 q 1-99 q 2$ & 118 & $100 \%$ \\
\hline Retail Sales (OECD, MEI) & $75 q 1-99 q 2$ & 98 & $83 \%$ & $70 q 1-99 q 2$ & 118 & $100 \%$ & $70 q 1-99 q 2$ & 118 & $100 \%$ \\
\hline Wholesale Sales (OECD, MEI) & $70 q 1-99 q 2$ & 118 & $100 \%$ & & & $0 \%$ & & & $0 \%$ \\
\hline Personal Consumption Expenditure (OECD, QNA) & $70 q 1-99 q 2$ & 118 & $100 \%$ & $75 q 1-97 q 4^{*}$ & 23 & $19 \%$ & $70 q 1-99 q 2$ & 118 & $100 \%$ \\
\hline Housing Starts, Construction put in place (OECD, MEI) & $70 q 1-99 q 1$ & 117 & $99 \%$ & & & $0 \%$ & & & $0 \%$ \\
\hline Permits Issued (OECD, MEI) & $70 q 1-99 q 1$ & 117 & $\mathbf{9 9} \%$ & $92 q 1-99 q 2$ & 30 & $25 \%$ & & & $0 \%$ \\
\hline Stocks of finished goods in manufacturing, Survey Assessme & $70 q 1-99 q 2$ & 118 & $100 \%$ & $75 q 1-99 q 2$ & 118 & $100 \%$ & $70 q 1-99 q 2$ & 118 & $100 \%$ \\
\hline Orders in manufacturing, Survey Assessment (EC Survey) & $70 q 1-99 q 2$ & 118 & $100 \%$ & $75 q 1-99 q 2$ & 118 & $100 \%$ & $70 q 1-99 q 2$ & 118 & $100 \%$ \\
\hline Book Orders, Survey Assessment (EC Survey) & $70 q 1-99 q 2$ & 118 & $100 \%$ & $75 q 1-99 q 2$ & 118 & $100 \%$ & $70 q 1-99 q 2$ & 118 & $100 \%$ \\
\hline Effective Exchange Rate (ECB Database) & $83 q 4-99 q 2$ & 66 & $56 \%$ & $83 q 4-99 q 2$ & 66 & $56 \%$ & $83 q 4-99 q 2$ & 66 & $56 \%$ \\
\hline Short-Term Interest Rates (Derived ECB database, and AMECO & $72 q 1-99 q 2(b)$ & 118 & $100 \%$ & $72 q 1-99 q 2(b)$ & 82 & $69 \%$ & $72 q 1-99 q 2(b)$ & 78 & $66 \%$ \\
\hline Long-Term Interest Rates (Derived ECB database) & $88 q 1-99 q 2(b)$ & 50 & $42 \%$ & $88 q 1-99 q 2(b)$ & 42 & $36 \%$ & $88 q 1-99 q 2(b)$ & 102 & $86 \%$ \\
\hline Money Stock M1 (ECB database) & $80 q 2-99 q 2$ & 78 & $66 \%$ & $80 q 2-99 q 2$ & 78 & $66 \%$ & $80 q 2-99 q 2$ & 78 & $66 \%$ \\
\hline Money Stock M2 (ECB database) & $80 q 2-99 q 2$ & 78 & $66 \%$ & $80 q 2-99 q 2$ & 78 & $66 \%$ & $80 q 2-99 q 2$ & 78 & $66 \%$ \\
\hline Money Stock M3 (ECB database) & $80 q 2-99 q 2$ & 78 & $66 \%$ & $80 q 2-99 q 2$ & 78 & $66 \%$ & $80 q 2-99 q 2$ & 78 & $66 \%$ \\
\hline Credit to non financial institutions (BIS) & $78 q 1-98 q 4$ & 84 & $71 \%$ & & & $0 \%$ & & & $0 \%$ \\
\hline Credit to Individuals (BIS) & $78 q 1-98 q 4$ & 84 & $71 \%$ & & & $0 \%$ & $89 q 3-99 q 2$ & 42 & $36 \%$ \\
\hline PPI Finished goods (OECD, MEI, and ECB database ${ }^{*}$ ) & $70 q 1-99 q 2$ & 118 & $100 \%$ & $85 q 1-99 q 2^{*}$ & 58 & $49 \%$ & $81 q 1-99 q 2$ & 114 & $97 \%$ \\
\hline WPI (ECB database and BIS*) & & & $0 \%$ & $70 q 1-99 q 1^{*}$ & 117 & $\mathbf{9 9 \%}$ & $89 q 1-98 q 4^{* \star}$ & 116 & $98 \%$ \\
\hline CPI (OECD, MEI) & $70 q 1-99 q 2$ & 118 & $100 \%$ & $70 q 1-99 q 2$ & 118 & $100 \%$ & $70 q 1-99 q 2$ & 118 & $100 \%$ \\
\hline Private Cons.Deflator (OECD, QNA) & $70 q 1-99 q 2$ & 118 & $100 \%$ & $75 q 1-97 q 4^{*}$ & 23 & $19 \%$ & $70 q 1-99 q 2$ & 118 & $100 \%$ \\
\hline GDP deflator (OECD, QNA) & $70 q 1-99 q 2$ & 118 & $100 \%$ & $75 q 1-97 q 4^{*}$ & 23 & $19 \%$ & $70 q 1-99 q 2$ & 118 & $100 \%$ \\
\hline Government Consumption Deflator (OECD, QNA) & $70 q 1-99 q 2$ & 118 & $100 \%$ & $75 q 1-97 q 4^{*}$ & 23 & $19 \%$ & $70 q 1-99 q 2$ & 118 & $100 \%$ \\
\hline Gross fixed capital formation Deflator (OECD, QNA) & $70 q 1-99 q 2$ & 118 & $100 \%$ & $75 q 1-97 q 4^{*}$ & 23 & $19 \%$ & $70 q 1-99 q 2$ & 118 & $100 \%$ \\
\hline Exports Deflator (OECD, QNA) & $70 q 1-99 q 2$ & 118 & $100 \%$ & $75 q 1-97 q 4^{*}$ & 23 & $19 \%$ & $70 q 1-99 q 2$ & 118 & $100 \%$ \\
\hline Imports Deflator (OECD, QNA) & $70 q 1-99 q 2$ & 118 & $100 \%$ & $75 q 1-97 q 4^{*}$ & 23 & $19 \%$ & $70 q 1-99 q 2$ & 118 & $100 \%$ \\
\hline Compensation of Employees (OECD,QNA) & $70 q 1-99 q 2$ & 118 & $100 \%$ & $75 q 1-97 q 4^{*}$ & 23 & $19 \%$ & $70 q 1-99 q 2$ & 118 & $100 \%$ \\
\hline Hourly Earnings (OECD, MEI) & $70 q 1-99 q 2$ & 118 & $100 \%$ & $75 q 1-99 q 2^{*}$ & 118 & $100 \%$ & $70 q 1-99 q 2$ & 118 & $100 \%$ \\
\hline Real Exports (OECD, QNA) & $70 q 1-99 q 2$ & 118 & $100 \%$ & $75 q 1-97 q 4^{*}$ & 23 & $19 \%$ & $70 q 1-99 q 2$ & 118 & $100 \%$ \\
\hline Real Imports (OECD, QNA) & $70 q 1-99 q 2$ & 118 & $100 \%$ & $75 q 1-97 q 4^{\star}$ & 23 & $19 \%$ & $70 q 1-99 q 2$ & 118 & $100 \%$ \\
\hline ULC (BIS) & $78 q 1-99 q 2$ & 86 & $73 \%$ & & & & $82 q 1-99 q 2$ & 70 & $59 \%$ \\
\hline TOTAL 35 Series & & 3654 & $88 \%$ & & 1957 & $47 \%$ & & 3418 & $83 \%$ \\
\hline
\end{tabular}

(a) Coverage stands for the ratio between available data and total number of observations.

(b) Some series have been rescalled and linked to other series as done to solve the German Unification issue and to have series that go as far as 1970 .

e.g.This was done for Long-term and Short-term interest rates using AMECO annual data for past data.

Quarterly data for Ireland for some series has been interpolated from annual data. (GDP, labour force, employment, personal consumption, all deflators, imports and exports). 


\begin{tabular}{|c|c|c|c|c|c|c|c|c|c|}
\hline \multirow{2}{*}{ Series } & \multicolumn{9}{|c|}{ Countries } \\
\hline & \multicolumn{3}{|c|}{ Netherlands } & \multicolumn{3}{|c|}{ Austria } & \multicolumn{3}{|c|}{ Portugal } \\
\hline & Availability & Observations & Coverage(a) & Availability & Observations & Coverage(a) & Availability & Observations & Coverage(a) \\
\hline Ind'I Production Total (OECD, MEI) & $70 q 1-99 q 1$ & 117 & $99 \%$ & $70 q 1-99 q 1$ & 117 & $\mathbf{9 9 \%}$ & $70 q 1-99 q 1$ & 117 & $99 \%$ \\
\hline Capacity Utilization (EC Surveys and OECD, MEI*) & $71 q 1-99 q 2$ & 119 & $101 \%$ & $96 q 1-99 q 2$ & 19 & $16 \%$ & $77 q 1-99 q 2^{*}$ & 90 & $76 \%$ \\
\hline GDP (OECD, QNA and BIS*) & $77 q 1-99 q 2$ & 90 & $76 \%$ & $70 q 1-99 q 2$ & 118 & $100 \%$ & $88 q 1-98 q 4$ & 116 & $98 \%$ \\
\hline Labour Force (OECD, Labour Stats. and BIS*) & $70 q 1-99 q 2^{*}$ & 30 & $25 \%$ & $70 q 1-98 q 4$ & 29 & $25 \%$ & $70 q 1-98 q 4$ & 29 & $25 \%$ \\
\hline Employment (OECD, Labour Stats. and BIS*) & $70 q 1-98 q 4^{*}$ & 29 & $25 \%$ & $70 q 1-98 q 4$ & 29 & $25 \%$ & $70 q 1-99 q 1^{*}$ & 119 & $101 \%$ \\
\hline Unemployment Rate (BIS) & $70 q 1-99 q 2$ & 118 & $100 \%$ & $70 q 1-99 q 2$ & 118 & $100 \%$ & $70 q 1-99 q 2$ & 118 & $100 \%$ \\
\hline Retail Sales (OECD, MEI) & $70 q 1-99 q 2$ & 118 & $100 \%$ & $73 q 1-99 q 2$ & 106 & $90 \%$ & $90 q 1-99 q 2$ & 38 & $32 \%$ \\
\hline Wholesale Sales (OECD, MEI) & & & $0 \%$ & & & $0 \%$ & & & $0 \%$ \\
\hline Personal Consumption Expenditure (OECD, QNA) & $77 q 1-99 q 2$ & 90 & $76 \%$ & $70 q 1-99 q 2$ & 118 & $100 \%$ & $88 q 1-98 q 4$ & 116 & $98 \%$ \\
\hline Housing Starts, Construction put in place (OECD, MEI) & $70 q 1-99 q 2$ & 118 & $100 \%$ & 96Q1-99q1 & 13 & $11 \%$ & & & $0 \%$ \\
\hline Permits Issued (OECD, MEI) & $70 q 1-99 q 1$ & 118 & $100 \%$ & & & $0 \%$ & $78 q 1-99 q 1$ & 85 & $72 \%$ \\
\hline Stocks of finished goods in manufacturing, Survey Assessme & $72 q 1-99 q 2$ & 118 & $100 \%$ & $85 q 1-99 q 2$ & 58 & $49 \%$ & $87 q 1-99 q 2$ & 50 & $42 \%$ \\
\hline Orders in manufacturing, Survey Assessment (EC Survey) & $72 q 1-99 q 2$ & 118 & $100 \%$ & $96 q 1-99 q 2$ & 14 & $12 \%$ & $87 q 1-99 q 2$ & 50 & $42 \%$ \\
\hline Book Orders, Survey Assessment (EC Survey) & $72 q 1-99 q 2$ & 118 & $100 \%$ & $85 q 1-99 q 2$ & 58 & $49 \%$ & $87 q 1-99 q 2$ & 50 & $42 \%$ \\
\hline Effective Exchange Rate (ECB Database) & $83 q 4-99 q 2$ & 66 & $56 \%$ & $83 q 4-99 q 2$ & 66 & $56 \%$ & $83 q 4-99 q 2$ & 66 & $56 \%$ \\
\hline Short-Term Interest Rates (Derived ECB database, and AMECO & $72 q 1-99 q 2(b)$ & 110 & $93 \%$ & $72 q 1-99 q 2(b)$ & 38 & $32 \%$ & $72 q 1-99 q 2(b)$ & 38 & $32 \%$ \\
\hline Long-Term Interest Rates (Derived ECB database) & $88 q 1-99 q 2(b)$ & 46 & $39 \%$ & $88 q 1-99 q 2(b)$ & 54 & $46 \%$ & $88 q 1-99 q 2(b)$ & 54 & $46 \%$ \\
\hline Money Stock M1 (ECB database) & $80 q 2-99 q 2$ & 78 & $66 \%$ & $80 q 2-99 q 2$ & 78 & $66 \%$ & $80 q 2-99 q 2$ & 78 & $66 \%$ \\
\hline Money Stock M2 (ECB database) & $80 q 2-99 q 2$ & 78 & $66 \%$ & $80 q 2-99 q 2$ & 78 & $66 \%$ & $80 q 2-99 q 2$ & 78 & $66 \%$ \\
\hline Money Stock M3 (ECB database) & $80 q 2-99 q 2$ & 78 & $66 \%$ & $80 q 2-99 q 2$ & 78 & $66 \%$ & $80 q 2-99 q 2$ & 78 & $66 \%$ \\
\hline Credit to non financial institutions (BIS) & & & $0 \%$ & & & $0 \%$ & & & $0 \%$ \\
\hline Credit to Individuals (BIS) & & & $0 \%$ & & & $0 \%$ & & & $0 \%$ \\
\hline PPI Finished goods (OECD, MEI, and ECB database ${ }^{*}$ ) & $76 q 1-99 q 2^{*}$ & 94 & $80 \%$ & $70 q 1-99 q 2$ & 118 & $100 \%$ & $90 q 1-99 q 2^{*}$ & 82 & $69 \%$ \\
\hline WPI (ECB database and BIS*) & & & $0 \%$ & $96 q 1-99 q 2^{* *}$ & 14 & $12 \%$ & & & $0 \%$ \\
\hline CPI (OECD, MEI) & $70 q 1-99 q 2$ & 118 & $100 \%$ & $76 q 1-99 q 2$ & 94 & $80 \%$ & $88 q 1-99 q 2$ & 46 & $39 \%$ \\
\hline Private Cons.Deflator (OECD, QNA) & $77 q 1-99 q 2$ & 90 & $76 \%$ & $76 q 1-99 q 2$ & 94 & $80 \%$ & $88 q 1-98 q 4$ & 116 & $98 \%$ \\
\hline GDP deflator (OECD, QNA) & $77 q 1-99 q 2$ & 90 & $76 \%$ & $76 q 1-99 q 2$ & 94 & $80 \%$ & $88 q 1-98 q 4$ & 116 & $98 \%$ \\
\hline Government Consumption Deflator (OECD, QNA) & $77 q 1-99 q 2$ & 90 & $76 \%$ & $76 q 1-99 q 2$ & 94 & $80 \%$ & $88 q 1-98 q 4$ & 116 & $98 \%$ \\
\hline Gross fixed capital formation Deflator (OECD, QNA) & $77 q 1-99 q 2$ & 90 & $76 \%$ & $76 q 1-99 q 2$ & 94 & $80 \%$ & $88 q 1-98 q 4$ & 116 & $98 \%$ \\
\hline Exports Deflator (OECD, QNA) & $77 q 1-99 q 2$ & 90 & $76 \%$ & $76 q 1-99 q 2$ & 94 & $80 \%$ & $88 q 1-98 q 4$ & 116 & $98 \%$ \\
\hline Imports Deflator (OECD, QNA) & $77 q 1-99 q 2$ & 90 & $76 \%$ & $76 q 1-99 q 2$ & 94 & $80 \%$ & $88 q 1-98 q 4$ & 116 & $98 \%$ \\
\hline Compensation of Employees (OECD,QNA) & $77 q 1-99 q 2$ & 90 & $76 \%$ & $70 q 1-99 q 2$ & 118 & $100 \%$ & & & $0 \%$ \\
\hline Hourly Earnings (OECD, MEI) & $70 q 1-99 q 2$ & 118 & $100 \%$ & $70 q 1-99 q 2$ & 118 & $100 \%$ & & & $0 \%$ \\
\hline Real Exports (OECD, QNA) & $77 q 1-99 q 2$ & 90 & $76 \%$ & $76 q 1-99 q 2$ & 94 & $80 \%$ & $88 q 1-98 q 4$ & 116 & $98 \%$ \\
\hline Real Imports (OECD, QNA) & $77 q 1-99 q 2$ & 90 & $76 \%$ & $76 q 1-99 q 2$ & 94 & $80 \%$ & $88 q 1-98 q 4$ & 116 & $98 \%$ \\
\hline $\operatorname{ULC}(\mathrm{BIS})$ & $84 q 1-99 q 2$ & 65 & $55 \%$ & & & $0 \%$ & & & $0 \%$ \\
\hline TOTAL 35 Series & & 2962 & $72 \%$ & & 2403 & $58 \%$ & & 2426 & $59 \%$ \\
\hline
\end{tabular}

(a) Coverage stands for the ratio between available data and total number of observations.

(b) Some series have been rescalled and linked to other series as done to solve the German Unification issue and to have series that go as far as 1970.

e.g.This was done for Long-term and Short-term interest rates using AMECO annual data for past data. 


\begin{tabular}{|c|c|c|c|}
\hline \multirow{2}{*}{ Series } & \multicolumn{3}{|c|}{ Finland } \\
\hline & Availability & Observations & Coverage $(a$ \\
\hline & $70 q 1-99 q 1$ & 117 & 0.99152542 \\
\hline Ind'I Production Total (OECD, MEI) & 80q1-99q2 & 83 & $70 \%$ \\
\hline Capacity Utilization (EC Surveys and OECD, MEI*) & $75 q 1-99 q 2$ & 98 & $83 \%$ \\
\hline GDP (OECD, QNA and BIS*) & $70 \mathrm{q} 1-99 \mathrm{q} 2^{*}$ & 118 & $100 \%$ \\
\hline Labour Force (OECD, Labour Stats. and BIS*) & $70 \mathrm{q} 1-99 \mathrm{q} 1^{*}$ & 117 & $99 \%$ \\
\hline Employment (OECD, Labour Stats. and BIS*) & $70 q 1-99 q 2$ & 118 & $100 \%$ \\
\hline Unemployment Rate (BIS) & $85 q 1-99 q 2$ & 58 & $49 \%$ \\
\hline Retail Sales (OECD, MEI) & $75 q 1-99 q 1$ & 97 & $82 \%$ \\
\hline Wholesale Sales (OECD, MEI) & $75 q 1-99 q 2$ & 98 & $83 \%$ \\
\hline Personal Consumption Expenditure (OECD, ONA) & $70 q 1-99 q 1$ & 117 & $99 \%$ \\
\hline Housing Starts, Construction put in place (OECD, MEI) & $70 q 1-99 q 1$ & 117 & $99 \%$ \\
\hline Permits Issued (OECD, MEI) & $93 q 1-99 q 2$ & 26 & $22 \%$ \\
\hline Stocks of finished goods in manufacturing, Survey Assessme & $85 q 1-99 q 2$ & 58 & $49 \%$ \\
\hline Orders in manufacturing, Survey Assessment (EC Survey) & $85 q 1-99 q 2$ & 58 & $49 \%$ \\
\hline Book Orders, Survey Assessment (EC Survey) & $83 q 4-99 q 2$ & 66 & $56 \%$ \\
\hline Effective Exchange Rate (ECB Database) & $90 q 1-99 q 2(b)$ & 46 & $39 \%$ \\
\hline Short-Term Interest Rates (Derived ECB database, and AMECO & $86 q 1-99 q 2(b)$ & 38 & $32 \%$ \\
\hline Long-Term Interest Rates (Derived ECB database) & $80 \mathrm{q} 2-99 \mathrm{q} 2$ & 78 & $66 \%$ \\
\hline Money Stock M1 (ECB database) & $80 \mathrm{q}-99 \mathrm{q} 2$ & 78 & $66 \%$ \\
\hline Money Stock M2 (ECB database) & $80 \mathrm{q} 2-99 \mathrm{q} 2$ & 78 & $66 \%$ \\
\hline Money Stock M3 (ECB database) & & & $0 \%$ \\
\hline Credit to non financial institutions (BIS) & & & $0 \%$ \\
\hline Credit to Individuals (BIS) & 70q1-99q2 & 118 & $100 \%$ \\
\hline PPI Finished goods (OECD, MEl, and ECB database*) & $70 \mathrm{q} 1-99 \mathrm{q} 2^{\star \star}$ & 118 & $100 \%$ \\
\hline WPI (ECB database and BIS*) & $70 q 1-99 q 2$ & 118 & $100 \%$ \\
\hline CPI (OECD, MEI) & $75 q 1-99 q 2$ & 98 & $83 \%$ \\
\hline Private Cons.Deflator (OECD, QNA) & $75 q 1-99 q 2$ & 98 & $83 \%$ \\
\hline GDP deflator (OECD, QNA) & $75 q 1-99 q 2$ & 98 & $83 \%$ \\
\hline Government Consumption Deflator (OECD, ONA) & $75 q 1-99 q 2$ & 98 & $83 \%$ \\
\hline Gross fixed capital formation Deflator (OECD, QNA) & $75 q 1-99 q 2$ & 98 & $83 \%$ \\
\hline Exports Deflator (OECD, QNA) & $75 q 1-99 q 2$ & 98 & $83 \%$ \\
\hline Imports Deflator (OECD, QNA) & $70 q 1-99 q 2$ & 118 & $100 \%$ \\
\hline Compensation of Employees (OECD, QNA) & $70 q 1-99 q 2$ & 118 & $100 \%$ \\
\hline Hourly Earnings (OECD, MEI) & $75 q 1-99 q 2$ & 98 & $83 \%$ \\
\hline Real Exports (OECD, QNA) & $75 q 1-99 q 2$ & 98 & $83 \%$ \\
\hline Real Imports (OECD, QNA) & $89 q 1-99 q 2$ & 42 & $36 \%$ \\
\hline ULC (BIS) & & 3080 & $75 \%$ \\
\hline TOTAL 35 Series & & 3084 & $75 \%$ \\
\hline
\end{tabular}

(a) Coverage stands for the ratio between available data and total number of observations.

(b) Some series have been rescalled and linked to other series as done to solve the German Unification issue

\begin{tabular}{|c|c|}
\hline Series & \begin{tabular}{|l|} 
Total Coverage ${ }^{(\mathrm{a})}$ \\
For Each Variable
\end{tabular} \\
\hline Ind'I Production Total (OECD, MEI) & $97.54 \%$ \\
\hline Capacity Utilization (EC Surveys and OECD, MEI*) & $77.88 \%$ \\
\hline GDP (OECD, QNA and BIS*) & $75.85 \%$ \\
\hline Labour Force (OECD, Labour Stats. and BIS*) & $54.75 \%$ \\
\hline Employment (OECD, Labour Stats. and BIS*) & $57.37 \%$ \\
\hline Unemployment Rate (BIS) & $92.54 \%$ \\
\hline Retail Sales (OECD, MEI) & $74.92 \%$ \\
\hline Wholesale Sales (OECD, MEI) & $18.22 \%$ \\
\hline Personal Consumption Expenditure (OECD, QNA) & $75.76 \%$ \\
\hline Housing Starts, Construction put in place (OECD, MEI) & $52.97 \%$ \\
\hline Permits Issued (OECD, MEI) & $58.98 \%$ \\
\hline Stocks of finished goods in manufacturing, Survey Assessme & $75.59 \%$ \\
\hline Orders in manufacturing, Survey Assessment (EC Survey) & $74.58 \%$ \\
\hline Book Orders, Survey Assessment (EC Survey) & $78.31 \%$ \\
\hline Effective Exchange Rate (ECB Database) & $55.93 \%$ \\
\hline Short-Term Interest Rates (Derived ECB database, and AMECO & $66.10 \%$ \\
\hline Long-Term Interest Rates (Derived ECB database) & $50.17 \%$ \\
\hline Money Stock M1 (ECB database) & $66.10 \%$ \\
\hline Money Stock M2 (ECB database) & $66.10 \%$ \\
\hline Money Stock M3 (ECB database) & $66.10 \%$ \\
\hline Credit to non financial institutions (BIS) & $22.88 \%$ \\
\hline Credit to Individuals (BIS) & $26.53 \%$ \\
\hline PPI Finished goods (OECD, MEI, and ECB database*) & $86.10 \%$ \\
\hline WPI (ECB database and BIS*) & $33.81 \%$ \\
\hline CPI (OECD, MEI) & $91.86 \%$ \\
\hline Private Cons.Deflator (OECD, QNA) & $73.47 \%$ \\
\hline GDP deflator (OECD, QNA) & $73.47 \%$ \\
\hline Government Consumption Deflator (OECD, QNA) & $73.47 \%$ \\
\hline Gross fixed capital formation Deflator (OECD, QNA) & $73.47 \%$ \\
\hline Exports Deflator (OECD, QNA) & $73.47 \%$ \\
\hline Imports Deflator (OECD, QNA) & $73.47 \%$ \\
\hline Compensation of Employees (OECD,QNA) & $67.37 \%$ \\
\hline Hourly Earnings (OECD, MEI) & $86.61 \%$ \\
\hline Real Exports (OECD, QNA) & $73.47 \%$ \\
\hline Real Imports (OECD, QNA) & $73.47 \%$ \\
\hline ULC (BIS) & $40.08 \%$ \\
\hline TOTAL Coverage of the 35 Series & $68 \%$ \\
\hline
\end{tabular}

and to have series that go as far as 1970. e.g. This was done for Long-term and Short-term interest rates using AMECO annual data for past data. 


\section{European Central Bank Working Paper Series}

I "A global hazard index for the world foreign exchange markets" by V. Brousseau and F. Scacciavillani, May 1999.

2 "What does the single monetary policy do? A SVAR benchmark for the European Central Bank" by C. Monticelli and O. Tristani, May 1999.

3 "Fiscal policy effectiveness and neutrality results in a non-Ricardian world" by C. Detken, May 1999.

4 "From the ERM to the euro: new evidence on economic and policy convergence among EU countries” by I. Angeloni and L. Dedola, May 1999.

5 “Core inflation: a review of some conceptual issues" by M. Wynne, May 1999.

6 "The demand for M3 in the euro area" by G. Coenen and J.-L. Vega, September 1999.

7 “A cross-country comparison of market structures in European banking” by O. de Bandt and E. P. Davis, September 1999.

8 “Inflation zone targeting" by A. Orphanides and V. Wieland, October 1999.

9 "Asymptotic confidence bands for the estimated autocovariance and autocorrelation functions of vector autoregressive models" by G. Coenen, January 2000.

10 "On the effectiveness of sterilized foreign exchange intervention" by R. Fatum, February 2000.

II "Is the yield curve a useful information variable for the Eurosystem?" by J. M. Berk and P. van Bergeijk, February 2000.

12 "Indicator variables for optimal policy" by L. E. O. Svensson and M. Woodford, February 2000.

I3 “Monetary policy with uncertain parameters” by U. Söderström, February 2000.

14 "Assessing nominal income rules for monetary policy with model and data uncertainty" by G. D. Rudebusch, February 2000.

15 “The quest for prosperity without inflation” by A. Orphanides, March 2000.

16 "Estimating the implied distribution of the future short term interest rate using the LongstaffSchwartz model” by P. Hördahl, March 2000.

17 "Alternative measures of the NAIRU in the euro area: estimates and assessment" by S. Fabiani and R. Mestre, March 2000.

I8 "House prices and the macroeconomy in Europe: Results from a structural VAR analysis" by M. lacoviello, April 2000. 
19 "The euro and international capital markets" by C. Detken and P. Hartmann, April 2000.

20 "Convergence of fiscal policies in the euro area" by O. De Bandt and F. P. Mongelli, May 2000.

21 "Firm size and monetary policy transmission: evidence from German business survey data" by M. Ehrmann, May 2000.

22 "Regulating access to international large value payment systems" by C. Holthausen and T. Rønde, June 2000.

23 "Escaping Nash inflation" by In-Koo Cho and T. J. Sargent, June 2000.

24 "What horizon for price stability" by F. Smets, July 2000.

25 "Caution and conservatism in the making of monetary policy" by P. Schellekens, July 2000.

26 "Which kind of transparency? On the need for clarity in monetary policy-making" by B. Winkler, August 2000.

27 "This is what the US leading indicators lead" by M. Camacho and G. Perez-Quiros, August 2000.

28 "Learning, uncertainty and central bank activism in an economy with strategic interactions" by M. Ellison and N. Valla, August 2000.

29 "The sources of unemployment fluctuations: an empirical application to the Italian case" by S. Fabiani, A. Locarno, G. Oneto and P. Sestito, September 2000.

30 "A small estimated euro area model with rational expectations and nominal rigidities" by G. Coenen and V. Wieland, September 2000.

31 "The disappearing tax base: Is foreign direct investment eroding corporate income taxes?" by R. Gropp and K. Kostial, September 2000.

32 "Can indeterminacy explain the short-run non-neutrality of money?" by F. De Fiore, September 2000.

33 "The information content of M3 for future inflation" by C. Trecroci and J. L. Vega, October 2000.

34 "Capital market development, corporate governance and the credibility of exchange rate pegs" by O. Castrén and T. Takalo, October 2000.

35 "Systemic risk: A survey" by O. De Bandt and P. Hartmann, November 2000.

36 "Measuring core inflation in the euro area" by C. Morana, November 2000.

37 "Business fixed investment: Evidence of a financial accelerator in Europe" by P. Vermeulen, November 2000. 
38 "The optimal inflation tax when taxes are costly to collect" by F. De Fiore, November 2000.

39 "A money demand system for euro area M3" by C. Brand and N. Cassola, November 2000.

40 "Financial structure and the interest rate channel of ECB monetary policy" by B. Mojon, November 2000.

41 "Why adopt transparency? The publication of central bank forecasts" by P. M. Geraats, January $200 \mathrm{I}$.

42 "An area-wide model (AWM) for the euro area" by G. Fagan, J. Henry and R. Mestre, January 200I.

43 "Sources of economic renewal: from the traditional firm to the knowledge firm" by D. R. Palenzuela, February $200 \mathrm{I}$.

44 "The supply and demand for eurosystem deposits - The first 18 months" by U. Bindseil and F. Seitz, February 2001.

45 "Testing the Rank of the Hankel matrix: a statistical approach" by G. Camba-Mendez and G. Kapetanios, February 200 I.

46 "A two-factor model of the German term structure of interest rates" by N. Cassola and J. B. Luís, February 2001.

47 "Deposit insurance and moral hazard: does the counterfactual matter?" by R. Gropp and J. Vesala, February 2001.

48 "Financial market integration in Europe: on the effects of EMU on stock markets" by M. Fratzscher, March 2001.

49 "Business cycle and monetary policy analysis in a structural sticky-price model of the euro area" by M. Casares, March 2001.

50 "Employment and productivity growth in service and manufacturing sectors in France, Germany and the US" by T. von Wachter, March 2001.

5I "The functional form of the demand for euro area MI" by L. Stracca, March 200 I.

52 "Are the effects of monetary policy in the euro area greater in recessions than in booms?" by G. Peersman and F. Smets, March 2001.

53 "An evaluation of some measures of core inflation for the euro area" by J.-L. Vega and M. A. Wynne, April 200I.

54 “Assessment criteria for output gap estimates" by G. Camba-Méndez and D. R. Palenzuela, April 200I.

55 "Modelling the demand for loans to the private sector in the euro area" by A. Calza, G. Gartner and J. Sousa, April 200I. 
56 "Stabilization policy in a two country model and the role of financial frictions" by E. Faia, April 200I.

57 "Model-based indicators of labour market rigidity" by S. Fabiani and D. Rodriguez-Palenzuela, April 200I.

58 "Business cycle asymmetries in stock returns: evidence from higher order moments and conditional densities" by G. Perez-Quiros and A. Timmermann, April 2001.

59 "Uncertain potential output: implications for monetary policy" by M. Ehrmann and F. Smets, April 200I.

60 "A multi-country trend indicator for euro area inflation: computation and properties" by E. Angelini, J. Henry and R. Mestre, April $200 \mathrm{I}$.

61 "Diffusion index-based inflation forecasts for the euro area" by E. Angelini, J. Henry and R. Mestre, April $200 \mathrm{I}$. 